NBER WORKING PAPER SERIES

\title{
THE EFFECTS OF COCAINE AND HEROIN PRICE ON DRUG-RELATED EMERGENCY DEPARTMENT VISITS
}

\author{
Dhaval Dave \\ Working Paper 10619 \\ http://www.nber.org/papers/w10619 \\ NATIONAL BUREAU OF ECONOMIC RESEARCH \\ 1050 Massachusetts Avenue \\ Cambridge, MA 02138 \\ June 2004
}

Funding for this research was provided by a grant from the Robert Wood Johnson Foundation's Substance Abuse Research Program to the National Opinion Research Center, University of Chicago. The author would like to thank Michael Grossman for valuable comments and suggestions. I am indebted to Judy Ball and the Substance Abuse and Mental Health Services Administration for providing the DAWN data. Financial support from the John M. Olin Foundation is gratefully acknowledged. The views expressed herein are those of the author(s) and not necessarily those of the National Bureau of Economic Research.

C)2004 by Dhaval Dave. All rights reserved. Short sections of text, not to exceed two paragraphs, may be quoted without explicit permission provided that full credit, including $(\subset$ notice, is given to the source. 
The Effects of Cocaine and Heroin Price on Drug-Related Emergency Department Visits Dhaval Dave NBER Working Paper No. 10619

June 2004

JEL No. I1

\section{$\underline{\text { ABSTRACT }}$}

This paper estimates the empirical relationship between the prices of cocaine and heroin and objective indicators of use. The set of outcomes is drug related hospital emergency department admissions where cocaine and heroin are cited, for 21 large U.S. metropolitan areas. These outcomes are superior to subjective self-reports, and are policy-relevant since they directly measure a large component of the health-care costs associated with heavy or chronic drug usage. Panel data methodology is used to identify the empirical link between drug prices and these indicators. Results indicate that health consequences associated with heavy or chronic drug use are negatively related to drug prices, an instrument of drug control policy. The elasticity of the probability of a cocaine mention with respect to own-price is estimated at -0.27 , and the corresponding elasticity for the probability of a heroin mention is -0.15 . The probability of any drug related episode, which captures polydrug usage, is also significantly negatively related to both cocaine and heroin prices. Cross-price effects are consistent with a complementary relationship between cocaine and heroin. Models indicate the presence of negative lagged price effects, confirming the strong addictive aspects of both drugs and the cumulative adverse effects of drug use on health.

\section{Dhaval Dave}

John M. Olin Postdoctoral Fellow

University of Pennsylvania, Wharton School

and NBER

365 Fifth Avenue, Suite 5318

New York, NY 10016-4309

ddave@gc.cuny.edu 


\section{Introduction}

Much of current drug control policy in the United States focuses on interdiction programs aimed at stopping the flow of drugs. The U.S. spends approximately $\$ 26$ billion a year towards apprehension and punishment of drug offenders, the bulk of this aimed at dealers and sellers (Office of National Drug Control Policy, 2001). ${ }^{1}$ From an economic perspective, such drug enforcement, by raising the cost of supplying drugs to the U.S. market, acts as a non-monetary tax and increases the transaction price of drugs. ${ }^{2}$ By the law of the downward-sloping demand function, the increase in price must reduce the consumption of illicit drugs. Hence, a critical question concerns the extent to which drug use responds to prices, especially heavy or problematic use. Since manipulating prices is one mode of control that the public sector can exercise on the market for addictive unhealthy substances, empirical estimates of the relation between price variations and illicit drug consumption are key to informing and shaping public policy.

This paper estimates the empirical relationship between the prices of cocaine and heroin and objective indicators of their use. Cocaine and heroin prices are computed from the System to Retrieve Drug Evidence (STRIDE), comprised of purchases made by Drug Enforcement Administration (DEA) agents during undercover operations. The set of outcomes is drug related emergency room admissions where cocaine and heroin are cited, derived from the Drug Abuse Warning Network (DAWN). A panel data methodology is used to identify the empirical link between cocaine and heroin prices and these indicators of heavy or chronic consumption.

While this study is related to the new and growing empirical literature dealing with the price sensitivity of illegal drug consumption, it improves upon the prior estimates in a number of ways. The illegal drug use indicators employed in much of the literature are based on self-reports and may

\footnotetext{
${ }^{1}$ Approximately $67 \%$ of the federal drug control budget is allocated to supply reduction activities.

${ }^{2}$ Costs for drug suppliers increase because: 1) they are forced to use underground distribution and transportation channels that can be hidden from authorities, 2) some drug shipments are captured by the authorities and destroyed, 3) suppliers are forced to use the threat of violence or other
} 
be measured inaccurately. In contrast, the indicators used in the present study are objective outcomes related to consumption. In the DAWN data, emergency department personnel identify whether cocaine or heroin was associated with a particular drug episode. Moreover, much of the literature, by relying on self-reported national surveys, does not consider consumption by certain subgroups, who may behave very differently from the population at large. The persons sampled in DAWN are not representative of the general population. In particular, the focus is on persons whose substance use resulted in a visit to a hospital emergency room. These individuals are much more likely to be hardcore or chronic users of drugs than an individual selected at random. Thus, they also impose the heaviest costs on society and are the target of much illegal drug policy. There were 19,698 deaths from drug-induced causes in 2000, up over $16 \%$ since 1998 . Health care costs associated with drug abuse were estimated at around $\$ 15$ billion for 2000 , an increase of almost 40 $\%$ since 1992 (ONDCP, 2003). In this respect, an estimate of the effect of drug prices on drug related emergency department (ED) episodes is valuable in that it directly relates drug prices, an instrument of enforcement efforts, to the health consequences of heavy drug use.

Many studies based on survey data also rely on the respondent's state of residence as the geographic unit. Consequently, when estimating price responsiveness, these researchers have had to employ a state-average price despite the fact that there is considerable inter-city variation in drug prices even within a given state. This measurement error may lead to biased estimates. The present study overcomes this limitation by computing and merging drug prices at the city level. This analysis further exploits the time-series of city cross sections and estimates various fixed-effects specifications to control for unmeasured factors that may be correlated with price and consumption. Another deficiency in the existing literature concerns cross price elasticities of demand. There are very few studies that analyze the effects of changes in the price of one drug on the consumption 
indicators of another. The present study informs on whether heroin and cocaine are substitutes or complements using the aforementioned objective drug use outcomes.

The remainder of the study proceeds as follows. Section 2 reviews prior empirical studies dealing with the price sensitivity of the consumption of illegal drugs. Section 3 describes the data assembled for use in this study. Section 4 outlines the analytical models that guide the empirical specifications. Section 5 discusses the econometric strategy for estimating the models. Section 6 presents the results, and section 7 offers some concluding remarks.

\section{Prior Studies}

An editorial in Drug and Alcohol Review (1999) stated that while economics has a critical influence in the development of policies in other areas, "illicit drugs is one of the few remaining areas yet to be significantly influenced by advances in this discipline." Yet, there is a rapidly growing empirical literature by economists dealing with the price sensitivity of consumption of illegal drugs. ${ }^{3}$ These demand studies primarily draw on illegal drug prices derived from local purchases made by drug enforcement agents while undercover. The studies typically combine these prices with self-reported measures of drug use from such national surveys as the National Household Survey of Drug Abuse and Monitoring the Future. The outcomes employed in these analyses are usually past year or past month participation and frequency of use given positive participation.

The early conventional view that the demand for addictive substances, such as illicit drugs, did not respond to price was increasingly challenged by subsequent studies. Roumasset and Hadreas (1977) believed that the demand for heroin was unitary elastic. Moore (1977) argued that the aggregate demand for heroin is likely to be price inelastic, but not perfectly price-inelastic, so that an increase in price will reduce consumption but also increase total expenditure. Silverman and

\footnotetext{
${ }^{3}$ Economists have also studied various issues concerning the current policy towards illicit drugs versus a regime where drugs are legalized. See, for example, MacCoun and Reuter (2001), Miron (2001), Becker, Grossman, and Murphy (2003), Kuziemko and Levitt (2001), and Lee (1993).
} 
Spruill (1977) implicitly estimate the long-run price elasticity of demand for heroin at -0.25 , based on monthly aggregated data for 41 poor, non-white Detroit communities from November 1970 to July 1973. Van Ours (1995) analyzes data on opium consumption and the number of opium users in the Dutch East Indies (now Indonesia) for the period 1923 to 1938. He estimates a short-run price elasticity of demand of -0.70 and a long-run price elasticity of demand of -1.00 . BrettevilleJensen and Sutton (1996) estimate the price-responsiveness for heroin to be -1.23 , based on a sample of non-dealing heroin users who participated in a needle exchange program in Oslo, Norway.

Several authors, in more recent studies, have estimated price elasticities using national survey data. Grossman and Chaloupka (1998) analyze the demand for cocaine by young adults (ages 17-29) in the Monitoring the Future (MTF) panels using the rational addiction framework. The data employed in their study consists of panels formed from nationally representative crosssectional surveys of high school seniors conducted between 1976 and 1985, with the last follow-up conducted in 1989. Grossman and Chaloupka find that annual participation and frequency of use given positive participation respond negatively to the price of cocaine. The long-run price elasticity of participation is estimated at -1.00 , and the long-run price elasticity of frequency given participation is estimated at -0.35 . They also find that current consumption is positively affected by past consumption, consistent with the hypothesis that cocaine is an addictive good, and also positively affected by future consumption, consistent with the rational addiction model.

Chaloupka, Grossman, and Tauras (1999) estimate cocaine price elasticities for past month and past year outcomes based on the 1982 and 1989 MTF cross-sectional surveys of high school seniors. Their results indicate a price elasticity of past-year participation of -0.89 and an elasticity of past-month participation of -0.98 . The corresponding frequency elasticities are -0.40 and -0.45 respectively. However, DiNardo (1993) finds that past-month participation by high school seniors does not respond to price in a similar MTF sample for the years $1977-1987$. 
Based on pooled data from the 1988, 1990, and 1991 National Household Surveys of Drug Abuse (NHSDA), Saffer and Chaloupka (1999a) estimate models for all ages. They find that the annual participation price elasticity for cocaine is -0.55 and that for heroin is -0.90 . Monthly participation price elasticities for cocaine and heroin are -0.80 and -0.36 respectively. Using the same sample, Saffer and Chaloupka (1999b) estimate these price elasticities separately for demographic subgroups. They find that the cocaine price elasticity is insignificant for blacks and Asians, -1.83 for Native Americans, and between -0.5 and -0.8 for white males, Hispanics, women, and youth. For heroin, the price elasticity is estimated at -1.63 for white males, -0.62 for females, 0.36 for youth, and close to zero for all others. DeSimone and Farrely (2001) analyze data from 1990-1997 NHSDA. They estimate a past-year cocaine participation elasticity of -0.41 for individuals between the ages of 18 to 39. However, similar models for persons ages 12 to 17 do not yield significantly negative price effects.

While the weight of the evidence from these studies suggests that cocaine and heroin use do respond negatively to price, there is little consensus about the magnitudes of the own-price elasticities. Studies that investigate the cross-price responsiveness of various illicit substances are sparse. Saffer and Chaloupka (1999a, 1999b), based on NHSDA data, estimate demand functions for cocaine, heroin, marijuana, and alcohol that contain the money price of each substance except marijuana. Their results show that these substances are economic complements, such that an increase in the price of one decreases the consumption of all others.

The illegal drug use indicators in the studies just cited may be plagued by inaccuracies if self-reports are subject to response error, and such surveys also fail to capture many hardcore drug users. ${ }^{4}$ These considerations have led researchers to consider the price sensitivity of outcomes

\footnotetext{
${ }^{4}$ Since drug use is significantly higher among respondents who live in households considered unstable, the NHSDA's bias towards sampling stable households is likely to overlook many heavy drug users. Many studies have documented that respondents in the NHSDA understate heavy drug use. The Substance Abuse and Mental Health Administration (SAMHSA) reports that virtually no heroin addicts respond in the NHSDA. A comparison of heavy cocaine users in the NHSDA
} 
related to drug consumption. Model (1993) finds that marijuana-related hospital emergency room episodes are positively related to marijuana decriminalization, based on quarterly data from 1975 to 1978 for 21 metropolitan statistical areas (MSA) in the Drug Abuse Warning Network (DAWN). This study capitalizes on the decriminalization of the possession of small amounts of marijuana by eleven U.S. states between 1973 and 1978. This presumably reduced the full price of marijuana. Model does not include the money price of marijuana or other drugs in her study. Caulkins (2001) estimates an elasticity of the number of hospital emergency room mentions for cocaine with respect to own-price of -1.30 and an elasticity of the number of hospital emergency room mentions for heroin with respect to own-price of -0.84. Caulkins employs an annual U.S. time series constructed from DAWN for the years 1978 to 1996 . His models simply regress the given outcomes on price and do not control for any other factors that may have varied over time or for time trends. As a result, they may be biased.

Crane, Rivolo, and Comfort (1997) employ aggregate time series from DAWN in order to estimate the price elasticity of demand for cocaine ranging from -0.29 to -0.63 . This study also fails to control for time trends. Hyatt and Rhodes (1995) find that cocaine price is negatively related to the number of cocaine emergency room episode mentions, from DAWN. While this study adds city indicators to control for unobserved factors at the city level, it also does not control for time trends or any other factors that may have shifted over time. Furthermore, the price of cocaine is not adjusted for inflation. Since year indicators are not included, this leads to biased estimates.

All of these studies, which employ DAWN to measure the price responsiveness of cocaine and heroin, estimate models that are misspecified due to lack of adequate controls. As a result, it is difficult to ascertain from these studies whether the negative correlation between the outcomes and price represents a true causal effect or whether it reflects a spurious correlation due to other

with those in other sources shows a marked difference with respect to demographic characteristics. In the NHSDA, incomes are higher, unemployment is lower, and fewer respondents report using 
unobserved factors. The specifications in this study include a full set of city and time indicators and interactions between city indicators and linear trends, along with various socio-economic variables, to control for unmeasured factors that may be simultaneously correlated with price and consumption. None of the studies reviewed has combined this fixed-effects specification with objective measures of drug use.

\section{Data}

The empirical work is based on objective outcomes related to cocaine and heroin consumption derived from the Drug Abuse Warning Network (DAWN). Since the early 1970's, DAWN has provided information on the use of emergency departments in the U.S. for the treatment of drug-related health problems. It is an ongoing national probability survey conducted annually in 21 large metropolitan areas by the Substance Abuse and Mental Health Services Administration. ${ }^{5}$ Due to various changes in sample design over the years, a consistent time-series of the 21 cities is available only from 1990 to $2001 .^{6}$ DAWN collects information on patients seeking hospital emergency department (ED) treatment related to their use of an illicit drug or the non-medical use of a legal drug. ${ }^{7}$ To be included in DAWN, the patient must be age 6 years or older, be treated in the hospital's emergency department, and have a problem induced by or related to drug use, regardless of when the drug ingestion occurred. Eligible hospitals in the DAWN sample are nonFederal, short-stay general hospitals that have a 24-hour emergency department. Within each participating facility, a trained reporter, usually a nurse or a member of the ED or medical records

more than one drug. Estimates of heavy drug use reported in the NHSDA are also difficult to reconcile with other data sources maintained by SAMHSA. See Rhodes et al. (2001). ${ }^{5}$ The DAWN cities are Atlanta, Baltimore, Boston, Buffalo, Chicago, Dallas, Denver, Detroit, Los Angeles, Miami, Minneapolis, New Orleans, New York City, Newark, Philadelphia, Phoenix, St. Louis, San Diego, San Francisco, Seattle, and Washington D.C.

${ }^{6}$ Additional data inconsistencies that arise due to changes in the number of eligible hospitals or changes in hospitals that report to DAWN are controlled by including in all models the fraction of total eligible hospitals in each MSA that participate in DAWN. Year effects will also capture any other breaks over time.

${ }^{7}$ By far, the most common reason cited for the drug-related ED visit in 2000 was overdose, in approximately $44 \%$ of the episodes. 
staff, is responsible for reviewing medical charts for indications noted by the treating physician that the episode was drug related.

A drug episode is defined as an emergency department visit that is directly related to the use of an illegal drug or the non-medical use of a legal drug. ${ }^{8}$ In addition, DAWN also identifies the substances associated with the drug abuse episodes. Up to four substances may be reported or "mentioned" for each drug-related episode; thus, the total number of mentions exceeds the number of episodes. ${ }^{9}$ Much of the time, however, only one drug is mentioned. Based on these data, a variable measuring the probability of a drug related episode is defined as total drug related ED episodes in each metropolitan statistical area (MSA) divided by population. For the sample analyzed in this study, there are 312 such episodes per 100,000 persons. Similar rates are also defined for cocaine mentions and heroin mentions. There are 118 cocaine mentions and 64 heroin mentions per 100,000 persons. DAWN medical crises occur in a small fraction of the drug abusing population. Data from the National Comorbidity Survey show that about six percent of the adult population was diagnosed with a drug abuse or dependence disorder in 1991. Applied to the mean MSA population for 1991, this translates to about 215,000 individuals with a drug disorder. The mean number of drug related episodes for the same year was 9,574. This means that about 22 additional serious abusers are required to generate one extra DAWN drug episode. Thus, these outcomes defined from DAWN are intended to capture serious health consequences related to hardcore drug use. Means for the DAWN sample are presented in Table 1.

Since the outcomes are measured at the city or MSA level, additional MSA-level socioeconomic variables are created and included in all models. Personal income per capita is derived from the Bureau of Economic Analysis website and deflated by the national consumer price index reported by the Bureau of Labor Statistics. Total MSA population is obtained from the U.S.

\footnotetext{
${ }^{8}$ Since one person may make repeated visits, the number ED episodes reported in DAWN is not synonymous with the number of individuals seeking such treatment.

${ }^{9}$ Alcohol is not noted separately. It is reported only when used in combination with illegal drugs.
} 
Bureau of Census. Indicators measuring the percentage of MSA population that is male, black, other race, Hispanic, ages 16 to 24, ages 25 to 54, high school graduate, and college graduate are constructed from the Current Population Survey March supplements. In order to capture local labor market conditions, the unemployment rate in each MSA is also included in all models. Data on unemployment are obtained from the Bureau of Labor Statistics, and in some cases also calculated from the March supplements of the Current Population Survey.

Indicators of local enforcement efforts are also appended. Variables measuring the probability of arrest for drug possession and drug sale are computed from the FBI's Uniform Crime Reporting System. ${ }^{10}$ Ideally, the probability of arrest is constructed by dividing the total number of arrests in each category by the total number of drug users and dealers in the MSA or some proxy for total drug activity. However, as there are no reliable estimates of the number of drug users and dealers by MSA, the denominator is proxied by total MSA population. Variables measuring the total number of arrests in each MSA due to any drug possession, any drug sale or trafficking, any drug-related violation, sale or trafficking in cocaine or opiates, and sale or trafficking in marijuana are used to create the corresponding arrest rates.

Data on cocaine and heroin prices are computed from purchases made by undercover drug enforcement agents. Information on these purchases including cost, weight, and purity is recorded by the Drug Enforcement Agency (DEA) in their System to Retrieve Information from Drug Evidence (STRIDE). The advantage of STRIDE's transaction-level data is that they directly reflect prices on the street. These prices are expected to be relatively accurate because any unreasonable price offer by a DEA agent may raise suspicion on the dealer's part and endanger the agent.

\footnotetext{
${ }^{10}$ Data in the Uniform Crime Reports are available at the county level. To obtain MSA-level data, total arrests in each county are summed and aggregated for all counties represented in an MSA. Using state-level arrest variables does not materially affect results.
} 
However, because the transactions are of varying size and quality, the cost of each drug must be standardized. ${ }^{11}$

Standardized prices of one pure gram of cocaine and heroin in a given metropolitan area for a given year are derived in the following manner: ${ }^{12}$

$$
\begin{aligned}
\log _{\text {Cost }_{i j t}}= & \pi_{0}+\pi_{1}\left(\log \text { Predicted Purity }_{\mathrm{ijt}}+\log \text { Weight }_{\mathrm{ijt}}\right)+\pi_{2 \mathrm{j}} \sum \mathrm{MSA}_{\mathrm{j}}+\pi_{3 \mathrm{t}} \sum \text { Year }_{\mathrm{t}} \\
& +\pi_{4 \mathrm{jt}} \sum \mathrm{MSA}_{\mathrm{j}} * \text { Year }_{\mathrm{t}}+\mathrm{v}_{\mathrm{ijt}}
\end{aligned}
$$

The subscripts denote the $\mathrm{i}^{\text {th }}$ transaction in the $\mathrm{j}^{\text {th }}$ MSA for year $\mathrm{t}$. Cost refers to the total cost of the purchase, weight is the total gram weight of the purchase, and purity is the weight of the pure drug found in the purchase as a fraction of the total purchase weight. MSA and Year refer to dichotomous indicators of each, and MSA*Year refers to indicators of the interaction between the two. Predicted Purity is obtained from a first-stage regression of actual purity on all of these other explanatory variables. ${ }^{13}$ The price of one pure gram of the drug in MSA $\mathrm{j}$ for year $\mathrm{t}$ is then imputed as:

$$
\exp \left(\pi_{0}+\pi_{2 \mathrm{j}}+\pi_{3 \mathrm{t}}+\pi_{4 \mathrm{jt}}\right)
$$

In the above procedure, purity is treated as endogenous because purchases may depend on expected rather than actual purity (Caulkins, 1994). Identification is achieved by constraining the coefficient on predicted purity to equal that on weight in the second-stage regression (see footnote 21 ). In this study, price series based on purity treated as exogenous and estimating (1) with the coefficients unconstrained were experimented with in all models. There are no material changes in the results or

\footnotetext{
${ }^{11}$ For instance, Caulkins and Padman (1993) and Rhodes et al. (1994) show that there are sizable discounts for "wholesale" or large quantity purchases of cocaine.

12 This procedure is also used in many other studies. See, for example, Grossman and Chaloupka (1988), DeSimone and Farrely (2001), and DeSimone (2001).

${ }^{13}$ Equation (1) can be justified by defining the price of one pure gram of drug as:

Price $=$ Cost $/(\text { Pure Quantity of Drug })^{\pi 1}$, where pure quantity is purity times total weight. Here $\pi_{1}$ captures any non-linear effects of quantity on price, for example due to quantity discounts. In loglinear form, this is Log Price $=\log$ Cost $-\pi 1$ Log Purity $-\pi 1$ Log Weight. It is assumed that the standardized price varies between cities and over time. Thus, Log Price $=a+b$ MSA $+c$ Year $+d$ $M A^{*}$ Year. Substituting this expression in the log-linear formulation results in an estimable form, equation (1).
} 
conclusions. Hence, all reported results are based on cocaine and heroin prices computed as outlined above.

STRIDE data are available from 1974 to 2001, and all years are used to impute the price series for the periods represented in DAWN. Excluding outliers, there are 93,784 cocaine transactions and 40,957 heroin transactions. ${ }^{14}$ In order to maximize the sample size in subsequent estimation, prices that are missing in any given MSA for any given year are imputed by the mean of the prices for all other available MSA's in that particular state. ${ }^{15}$ Results are not sensitive to this imputation. All price series are deflated by the national CPI. The mean real price (in 1982-1984 dollars) of one pure gram of cocaine is $\$ 80.70$. The mean real heroin price is $\$ 451.08$.

One of the advantages of this study is that the drug prices are computed and merged at the city level. Many prior studies relying on national self-reported survey data used state-average prices despite the fact that drug prices seem to vary widely from city to city. Granted that there may still be substantial intra-city variation in drug prices at any given time, the measurement error is likely to be much smaller than with state-level prices. ${ }^{16}$

Kuziemko and Levitt (2001) find that STRIDE cocaine prices from 1986 through 1996 are positively related to state-level indicators of the certainty of punishment, measured by the per capita number of drug arrests, and the severity of punishment, measured by the fraction of drug arrests resulting in imprisonment. These findings suggest that illicit drug prices are responsive to enforcement and apprehension, instruments of current drug control policy. Basov, Jacobson, and Miron (2001) argue that due to the illicit, secretive nature of the drug trade, both production and

\footnotetext{
${ }^{14}$ Transactions used in the imputation have a purchase cost of at least one dollar (zero cost represents seizures and are thus excluded) and purity between zero and $100 \%$.

${ }^{15}$ This imputation is more relevant for heroin prices due to more missing data; about three percent of the DAWN sample are affected by this imputation. For cocaine, the DAWN sample is not affected.

${ }^{16}$ A report by the National Research Council (Manski, Pepper, and Petrie, 2001) criticizes STRIDE price data precisely for this reason, that there are substantial differences in these prices even within cities. Horowitz (2001) notes that because the purchases in STRIDE are motivated by criminal investigations, they do no represent a random sample of drug prices in the U.S.
} 
sales are more labor intensive compared to legal markets. Most of these jobs are also likely to be filled by low-skilled employees, youths, or others with fewer outside opportunities. Their study shows that cocaine and heroin prices from STRIDE are positively related to the state-specific relative unskilled wage in a time series of states from 1974 to 1999. These two studies further confirm that DEA drug prices do indeed reflect costs of retailing including expected penalties associated with this activity and labor costs.

\section{Analytical Framework}

The objective of this study is to assess the extent to which outcomes related to cocaine and heroin consumption respond to cocaine and heroin prices. Since illicit drugs are ultimately consumer goods, this question can be framed within the context of consumer theory and demand analysis. A simple utility framework yields the following current-period demand functions for the addictive good, specified in linear form: ${ }^{17}$

$$
A_{t}=\alpha_{1} P_{t}+\beta_{1} I_{t}+\beta_{2} Y_{t}+\varepsilon_{t}
$$

$$
A_{1 t}=\alpha_{1} P_{1 t}+\alpha_{2} P_{2 t}+\beta_{1} I_{t}+\beta_{2} Y_{t}+\varepsilon_{t}
$$

Equation (4) states that the demand for any illicit drug $\left(\mathrm{A}_{1}\right)$ depends on its own price $\left(\mathrm{P}_{1}\right)$, the price of the other drug $\left(\mathrm{P}_{2}\right)$, income $(\mathrm{I})$, and other characteristics $(\mathrm{Y})$ such as the individual's age, gender, race, and education. The parameter of interest, $\alpha_{1}$, is hypothesized to be negative under the law of the downward sloping demand function. The cross-price effect $\alpha_{2}$ is positive if the two drugs are economic substitutes, negative if they are economic complements, and zero if the two drugs are independent.

The utility function can be reformulated to explicitly take account of the addictive aspects of illicit drugs.

$$
\mathrm{U}_{\mathrm{t}}=\mathrm{U}_{\mathrm{t}}\left(\mathrm{A}_{1 \mathrm{t}}, \mathrm{A}_{2 \mathrm{t}}, \mathrm{S}_{1 \mathrm{t}}, \mathrm{S}_{2 \mathrm{t}}, \mathrm{X}_{\mathrm{t}}\right)
$$

Nonetheless, as long as the sampling problems associated with STRIDE are stable over time, these data can still accurately capture changes in the cost of drugs. 
The individual's current utility now depends on current consumption of the addictive goods ( $\mathrm{A}_{1}$ and $\left.\mathrm{A}_{2}\right)$, the non-addictive good $(\mathrm{X})$, and also on the stock of the addictive goods $\left(\mathrm{S}_{1}\right.$ and $\left.\mathrm{S}_{2}\right)$ accumulated through past consumption. In addition to positive but diminishing marginal utility in A and $\mathrm{X}$, the utility function also satisfies certain other restrictions. First, the stocks of addictive consumption positively affect current marginal utility of the addictive goods. This is the reinforcement effect by which past consumption of drugs stimulates current consumption.

$$
\begin{aligned}
& \mathrm{U}_{\mathrm{A} 1 \mathrm{~S} 1}=\partial_{2} \mathrm{U}_{\mathrm{t}} / \partial \mathrm{A}_{1 \mathrm{t}} \mathrm{S}_{1 \mathrm{t}}>0 \\
& \mathrm{U}_{\mathrm{A} 2 \mathrm{~S} 2}=\partial_{2} \mathrm{U}_{\mathrm{t}} / \partial \mathrm{A}_{2 \mathrm{t}} \mathrm{S}_{2 \mathrm{t}}>0
\end{aligned}
$$

Second, the stocks of addictive consumption negatively affect current total utility. This is the tolerance effect. Higher past addictive consumption lowers current utility, and hence a greater amount of current addictive consumption is required to obtain a given level of total utility. Alternatively, this can also reflect harmful addiction since past consumption of drugs can lower current utility due to detrimental health effects.

$$
\begin{aligned}
& \mathrm{U}_{\mathrm{S} 1}=\partial \mathrm{U}_{\mathrm{t}} / \partial \mathrm{S}_{1 \mathrm{t}}<0 \\
& \mathrm{U}_{\mathrm{S} 2}=\partial \mathrm{U}_{\mathrm{t}} / \partial \mathrm{S}_{2 \mathrm{t}}<0
\end{aligned}
$$

It is conceivable that there may also be cross-reinforcement effects so that the addictive stock of one drug may affect the current consumption of the other by affecting its current marginal utility.

(11) $\quad \mathrm{U}_{\mathrm{A} 2 \mathrm{~S} 1}=\partial_{2} \mathrm{U}_{\mathrm{t}} / \partial \mathrm{A}_{2 \mathrm{t}} \mathrm{S}_{1 \mathrm{t}} \geq 0$

Maximizing the above utility function in every period subject to a basic budget constraint derives a demand function where current consumption of the addictive good is now also affected by the addictive stock in addition to price, income, and other factors. ${ }^{18}$

$$
A_{t}=\alpha_{1} P_{t}+\delta_{1} S_{t}+\beta_{1} I_{t}+\beta_{2} Y_{t}+\varepsilon_{t}
$$

${ }^{17}$ Equation (3) assumes one addictive good as an argument in the utility function, and equation (4) assumes two addictive goods in the utility function.

${ }^{18}$ Equation (12) is based on a utility function with one addictive substance. 


$$
A_{1 t}=\alpha_{1} P_{1 t}+\alpha_{2} P_{2 t}+\delta_{1} S_{1 t}+\delta_{2} S_{2 t}+\beta_{1} I_{t}+\beta_{2} Y_{t}+\varepsilon_{t}
$$

The parameter $\delta_{1}$ is hypothesized to be greater than zero due to the positive reinforcement of past addictive consumption on current consumption. This intertemporal complementarity between past and current consumption is the hallmark of economic models of addiction. ${ }^{19}$ As before, the ownprice effect $\alpha_{1}$ is negative, the cross-price effect $\alpha_{2}$ depends on whether the drugs are substitutes, complements, or independent, and the cross-reinforcement effect $\delta_{2}$ may be zero or positive. ${ }^{20}$

\section{Empirical Framework}

The set of outcomes employed from DAWN is the number of times cocaine and heroin are cited in drug related emergency room episodes, divided by total MSA population. DAWN does not sample all eligible hospitals. Ideally, the probability of having a cocaine or heroin induced ED episode should be measured relative to the at-risk population, that is individuals living in an area within a sampled MSA that directs medical crises to a participating DAWN ER (Model, 1993). This probability can be written as:

$$
\operatorname{Prob}(\text { Mention } \mid \text { Total Pop })=\operatorname{Prob}(\text { Mention } \mid \text { At-Risk Pop }) * \operatorname{Prob}(\text { At-Risk Pop } \mid \text { Total Pop) }
$$

The probability of a drug mention relative to the appropriate at-risk population can be further expressed as:

$$
\begin{aligned}
\operatorname{Prob}(\text { Mention } \mid \text { At-Risk Pop })= & \operatorname{Prob}(\text { Report } \mid \text { At-Risk Pop, ED, Crisis, Use }) * \\
& \operatorname{Prob}(\text { ED } \mid \text { At-Risk Pop, Crisis, Use }) * \\
& \text { Prob(Crisis } \mid \text { At-Risk Pop, Use })^{*} \\
& \text { Prob(Use } \mid \text { At-Risk Pop })
\end{aligned}
$$

\footnotetext{
${ }^{19}$ This model is referred to as myopic addiction in the literature. Even though addiction is formulated explicitly through interactions between past and current consumption and has harmful effects in future periods, the individual is still myopic in that he is maximizing a single period utility function subject to a period budget constraint. See Becker and Murphy (1988) for a model of rational addiction wherein the individual maximizes a lifetime utility function comprised of a summation of discounted period utilities, similar to that specified in (5).

${ }^{20}$ In contrast to a cross-reinforcement effect, a cross-dampening effect would mean that (10) and (11) are negative; that is, an increase in the addictive stock of one drug lowers the current marginal utility of the other. In this case, $\delta_{2}$ is also negative. Since both cocaine and heroin disrupt the flow
} 
Substituting (15) into (14) and taking the log of both sides results in

$$
\begin{aligned}
\log \text { Prob(Mention } \mid \text { Total Pop })= & \text { Log Prob(Report } \mid \text { At-Risk Pop, ED, Crisis, Use })+ \\
& \text { Log Prob(ED } \mid \text { At-Risk Pop, Crisis, Use })+ \\
& \text { Log Prob(Crisis } \mid \text { At-Risk Pop, Use })+ \\
& \text { Log Prob(Use } \mid \text { At-Risk Pop })+ \\
& \text { Log Prob(At-Risk Pop } \mid \text { Total Pop })
\end{aligned}
$$

This identity stresses that many factors contribute to a DAWN drug mention. First, an individual must be part of the at-risk population and using drugs. He must then experience some crisis or medical emergency which results in a visit to a participating ER. Finally, hospital personnel must identify this episode as drug related. The probability of drug use and the probability of crisis (which is a monotonic function of the intensity of use) depend on the demand factors derived earlier. The probability of being part of the at-risk population relative to the total population is proxied by the number of hospitals participating in DAWN as a fraction of total eligible hospitals. The conditional probabilities of an ED visit and a drug report are related to emergency room visitation practices and any non-reporting or misreporting. There is no a priori reason to believe that these probabilities have systematically varied over time within cities; thus, they may be modeled as part of the unobserved area and year effects. These substitutions yield the following estimable specifications, which can be interpreted as reduced-form "production functions" for drugrelated emergency department visits, based on the demand functions derived in the previous section.

$$
\begin{aligned}
& \log \left(A_{i t} / 1-A_{i t}\right)=\alpha_{1} P_{i t}+\beta_{1} I_{i t}+\beta_{2} Y_{i t}+\beta_{3} R_{i t}+\varepsilon_{i t} \\
& \log \left(A_{1 i t} / 1-A_{1 i t}\right)=\alpha_{1} P_{1 i t}+\alpha_{2} P_{2 i t}+\beta_{1} I_{i t}+\beta_{2} Y_{i t}+\beta_{3} R_{i t}+\varepsilon_{i t}, \\
& \text { where } \varepsilon_{i t}=\mu_{i}+\eta_{t}+v_{i t}
\end{aligned}
$$

Equations (17) and (18) represent the drug-related emergency department visits production functions assuming the baseline demand models (3) and (4), with own and cross-price effects. The 
subscripts denote the $i^{\text {th }}$ MSA for year $t$. Y represents the vector of observable determinants of use, besides price and income, and is proxied by the unemployment rate, various MSA-level socioeconomic characteristics, and drug-related arrest rates. All models also include the log of the hospital response rate, $\mathrm{R}_{\mathrm{it}}$. The disturbance is modeled with two-way error components where $\mu_{\mathrm{i}}$ denotes the unobservable area fixed effects, $\eta_{\mathrm{t}}$ denotes the unobservable time effects, and $v_{\mathrm{it}}$ is the remainder stochastic error term. All regressions are estimated in logistic form, where the dependent variable is measured as the log of the odds ratio. Since the original outcomes are rates between zero and one, the logistic transformation ensures that the predicted rate or probability also lies in this range. $^{21}$ In an aggregated logistic regression, the variance of the error term is inversely proportional to $A_{i t}\left(1-A_{i t}\right) n_{i t}$. Thus, all models are weighted by $A_{i t}\left(1-A_{i t}\right) n_{i t}$ to correct for the heteroscedasticity. These fixed-effects specifications combined with a rich set of MSA covariates have not been estimated for DAWN in the prior literature. This formulation is followed in all estimations. ${ }^{22}$

The addictive demand framework yields the following specifications:

$$
\begin{aligned}
& \log \left(\mathrm{A}_{\mathrm{it}} / 1-\mathrm{A}_{\mathrm{it}}\right)=\alpha_{1} \mathrm{P}_{\mathrm{it}}+\delta_{1} \mathrm{~S}_{\mathrm{it}}+\beta_{1} \mathrm{I}_{\mathrm{it}}+\beta_{2} \mathrm{Y}_{\mathrm{it}}+\beta_{3} \mathrm{R}_{\mathrm{it}}+\mu_{\mathrm{i}}+\eta_{\mathrm{t}}+v_{\mathrm{it}} \\
& \log \left(\mathrm{A}_{1 \mathrm{it}} / 1-\mathrm{A}_{1 \mathrm{it}}\right)=\alpha_{1} \mathrm{P}_{1 \mathrm{it}}+\alpha_{2} \mathrm{P}_{2 \mathrm{it}}+\delta_{1} \mathrm{~S}_{1 \mathrm{it}}+\delta_{2} \mathrm{~S}_{2 \mathrm{it}}+\beta_{1} \mathrm{I}_{\mathrm{it}}+\beta_{2} \mathrm{Y}_{\mathrm{it}}+\beta_{3} \mathrm{R}_{\mathrm{it}}+\mu_{\mathrm{i}}+\eta_{\mathrm{t}}+v_{\mathrm{it}}
\end{aligned}
$$

reinforcement effect theoretically seems more likely.

${ }^{21}$ The elasticity of the probability of a drug-related ED visit with respect to price is calculated as $\alpha_{1}$ $(1-A) P$. The marginal effect of price on this probability is $\alpha_{1}(1-A) A$.

22 In estimating these "reduced-form" production functions based on underlying addictive demand, it is assumed that the U.S. supply of cocaine and heroin is infinitely elastic, that is suppliers are able to satisfy any market demand at the current price. This assumption is invoked in virtually all empirical studies of the demand for drugs. Cocaine and heroin are basically agricultural products that are inexpensive to produce and require minimal processing. Rhodes et al. (2001) note that cocaine, for instance, is fairly easy to transport and only about 300 metric tons satisfy entire U.S. market demand. The largest costs involved in producing, transporting, and distributing cocaine are the costs of operating in the illegal sector. Miron (2001) suggests that the black market price of cocaine is as much as 5 times higher and that of heroin as much as 19 times higher than prices that would prevail in a legalized regime. The amount of coca harvested exceeds the amount shipped by a substantial amount. This implies that suppliers can draw on this excess capacity to satisfy any expansions in market demand without increasing their per unit cost. Basov, Jacobson, and Miron (2001) similarly note that the U.S. is also a relatively small market for opiates. All of these considerations point to the domestic supply curves for cocaine and heroin being highly elastic. The more relevant consideration of policy endogeneity is addressed below. 
In estimating (19) and (20), since the accumulated addictive stocks of each drug are unobserved, they can be proxied by past consumption, which in turn can be proxied by the past prices of drugs. Thus, under an addiction paradigm, current drug-related outcomes will be a function of contemporaneous and past drug prices.

$$
\begin{aligned}
& \log \left(\mathrm{A}_{\mathrm{it}} / 1-\mathrm{A}_{\mathrm{it}}\right)=\alpha_{1} \mathrm{P}_{\mathrm{it}}+\lambda_{1} \mathrm{P}_{\mathrm{it}-1}+\beta_{1} \mathrm{I}_{\mathrm{it}}+\beta_{2} \mathrm{Y}_{\mathrm{it}}+\beta_{3} \mathrm{R}_{\mathrm{it}}+\mu_{\mathrm{i}}+\eta_{\mathrm{t}}+v_{\mathrm{it}} \\
& \log \left(\mathrm{A}_{1 \mathrm{it}} / 1-\mathrm{A}_{1 \mathrm{it}}\right)=\alpha_{1} \mathrm{P}_{1 \mathrm{it}}+\alpha_{2} \mathrm{P}_{2 \mathrm{it}}+\lambda_{1} \mathrm{P}_{1 \mathrm{it}-1}+\lambda_{2} \mathrm{P}_{2 \mathrm{it}-1}+\beta_{1} \mathrm{I}_{\mathrm{it}}+\beta_{2} \mathrm{Y}_{\mathrm{it}}+\beta_{3} \mathrm{R}_{\mathrm{it}}+\mu_{\mathrm{i}}+\eta_{\mathrm{t}}+v_{\text {it }}
\end{aligned}
$$

An alternative rationale for (21) and (22) is that drug-related health emergencies are produced not just by current use but also by the cumulative effects of past use, which is a function of past prices.

These fixed-effects procedures are inconsistent if city drug prices or the policies that determine them might depend on outcomes related to substance use, or as is more likely the lagged drug-related outcomes. This possibility is sometimes referred to as policy endogeneity. There are two critical issues. The first is that there is an unmeasured fixed effect that is correlated with righthand-side variables. In the context of this research, the fixed effect may be city or state sentiment (e.g., religiosity) towards drug use that also influences drug prices and enforcement. The second issue is that price may be predetermined and not strictly exogenous because past shocks to drug use or drug-related health emergencies may be correlated with current prices. Thus, current price is predetermined in that it is uncorrelated with the current disturbance term but correlated with all past disturbances.

$$
\mathrm{E}\left(\mathrm{P}_{\text {it }} v_{\text {is }}\right) \neq 0 \text { for } \mathrm{s}<\mathrm{t} \text { and } \mathrm{E}\left(\mathrm{P}_{\text {it }} v_{\text {is }}\right)=0 \text { for } \mathrm{s} \geq \mathrm{t}
$$

Consider the baseline demand equation (17). For convenience, $\operatorname{LO}_{\text {it }}$ refers to $\log \left(\mathrm{A}_{\mathrm{it}} / 1-\mathrm{A}_{\mathrm{it}}\right)$ and the year effects are ignored.

$$
\mathrm{LO}_{\text {it }}=\alpha_{1} \mathrm{P}_{\mathrm{it}}+\beta_{1} \mathrm{I}_{\mathrm{it}}+\beta_{2} \mathrm{Y}_{\mathrm{it}}+\beta_{3} \mathrm{R}_{\mathrm{it}}+\mu_{\mathrm{i}}+v_{\mathrm{it}}
$$

The area fixed effects can be removed by first differencing. ${ }^{23}$

\footnotetext{
${ }^{23}$ Fixed-effects estimation is equivalent to first-differencing if there are exactly two periods for each cross-section. Otherwise, including fixed effects is equivalent to a regression where all
} 
(17a)

$$
\mathrm{LO}_{\mathrm{it}}-\mathrm{LO}_{\mathrm{it}-1}=\alpha_{1}\left(\mathrm{P}_{\mathrm{it}}-\mathrm{P}_{\mathrm{it}-1}\right)+\beta_{1}\left(\mathrm{I}_{\mathrm{it}}-\mathrm{I}_{\mathrm{it}-1}\right)+\beta_{2}\left(\mathrm{Y}_{\mathrm{it}}-\mathrm{Y}_{\mathrm{it}-1}\right)+\beta_{3}\left(\mathrm{R}_{\mathrm{it}}-\mathrm{R}_{\mathrm{it}-1}\right)+\left(v_{\mathrm{it}}-v_{\mathrm{it}-1}\right)
$$

If price is a predetermined variable then the orthogonality assumption is violated since $\mathrm{P}_{\mathrm{it}}$ is correlated with $v_{\text {it-1 }}$. The fixed-effects or first-differenced specification is no longer consistent.

In order to check for potential policy endogeneity, two informal tests are performed. First, following Model (1993), specifications with a series of lagged and leading prices are estimated. If changes in drug outcomes are caused by changes in enforcement or prices as opposed to changes in prices being causes by these outcomes, then larger outcomes should not occur until after any decreases in price and vice versa. In specifications with lagged and leading price series, only the coefficients on contemporaneous and lagged prices should be significant. The lead prices should be insignificant. If the leading prices are significant, however, this could be evidence of policy endogeneity. ${ }^{24}$

A second informal test estimates specifications with various lagged enforcement variables to proxy for past shocks to demand that may also be affecting current prices. Consider the baseline equation again, where the disturbance term is divided into two components.

$$
\mathrm{LO}_{\mathrm{it}}=\alpha_{1} \mathrm{P}_{\mathrm{it}}+\beta_{1} \mathrm{I}_{\mathrm{it}}+\beta_{2} \mathrm{Y}_{\mathrm{it}}+\beta_{3} \mathrm{R}_{\mathrm{it}}+\mu_{\mathrm{i}}+v_{\mathrm{it}} \text {, where } v_{\mathrm{it}}=\omega_{\mathrm{it}}+\varphi_{\mathrm{it}}
$$

Thus,

$$
\begin{array}{r}
L O_{i t}-L_{i t-1}=\alpha_{1}\left(P_{i t}-P_{i t-1}\right)+\beta_{1}\left(I_{i t}-I_{i t-1}\right)+\beta_{2}\left(Y_{i t}-Y_{i t-1}\right)+\beta_{3}\left(R_{i t}-R_{i t-1}\right)+ \\
\left(\omega_{i t}-\omega_{i t-1}\right)+\left(\varphi_{i t}-\varphi_{i t-1}\right)
\end{array}
$$

Here, $\varphi_{\mathrm{it}}$ is a pure stochastic disturbance term that is uncorrelated with all past, current, and future values of the explanatory variables. However, $\omega_{\mathrm{it}}$ represents unobserved shocks to past use that may also affect current prices, making price predetermined and statistically endogenous. This endogeneity is similar to omitted variables bias in an intertemporal context. In other words, there

observations are transformed to deviations from the mean, where the mean is calculated for each cross-section over all periods. For this exposition, the distinction is not important.

${ }^{24}$ Significant lead prices may also be construed as evidence of rational addiction. However in the present context, it is unlikely that users are able to forecast drug prices far in advance, as much as one year. See Gruber and Koszegi (2001). 
are unmeasured factors $\omega$ that simultaneously affect past demand and current prices. Conditional on $\omega$, price is strictly exogenous with respect to the remainder disturbance term. Therefore, if variables measuring such shocks can be included in the models, then the coefficients on price can be analyzed to gauge the extent of such endogeneity. Past enforcement efforts may proxy for these shocks to some extent. For instance, higher arrest rates related to drug violations or sales may affect current drug consumption and also influence future drug prices. If the price effects are robust in specifications that control for these lagged enforcement variables, then it is likely that price is not predetermined and may be regarded as strictly exogenous. In addition, including city specific trends in the models may also control for some of these unobserved shocks.

The elasticity of drug mentions with respect to drug use is unambiguously positive, since the negative health consequences of addictive consumption are well documented. ${ }^{25}$ Also, by definition, the majority of the ED episodes and mentions in the DAWN sample are causally related to drugs. Thus, the sign and significance of the estimated elasticity of a drug mention with respect to price informs on the unobserved price elasticity of problematic drug use. The price elasticity of drug episodes and mentions is also relevant because it measures the direct "reduced-form" effect of drug prices (an instrument of enforcement and public policy) on health.

\section{Results}

Before turning to the results, Figures 1 through 4 visually depict the strong negative relationship between cocaine and heroin related ED episodes and drug prices. Figure 1 shows the total drug-related ED episodes in the 21 MSA's and the mean cocaine price in these cities. Figure 2 plots these total drug episodes against the mean heroin price. Both reveal that total ED drug episodes increased from 1990 to 2001 as the prices of cocaine and heroin declined. ${ }^{26}$ Figure 3

\footnotetext{
${ }^{25}$ See The Economic Costs of Alcohol and Drug Abuse in the United States 1992 (Harwood et al., 1998)

${ }^{26}$ The decline in real cocaine price has been attributed to the development of a production sector and the learning-by-doing that followed the reintroduction of cocaine into the U.S. market in the 1970 s after prolonged absence. There was also vertical integration in the chain of distribution,
} 
graphs the total cocaine mentions versus the mean cocaine price, and Figure 4 graphs the total heroin mentions versus the mean heroin price. The striking point is that the series of cocaine and heroin mentions are virtual mirror images of the price series. This is only suggestive since these figures do not control for time trends or other confounders. The multivariate models, presented next, address this possibility.

Table 2 presents estimation of the baseline production function given by equation (17) for the log of the odds of a cocaine mention. All specifications include the drug price, MSA-level socioeconomic covariates, the DAWN response rate, year effects, and then progressively add MSA effects and MSA-specific linear trends. Cocaine price is negative and statistically significant in all specifications, and the elasticity of the probability of a cocaine mention with respect to own price ranges from -0.18 to -0.27 . Specification 1 , which includes year indicators, yields a price elasticity of -0.25 . The coefficient on income is significantly positive. While this implies that health, at least as defined here, is an inferior good, this is probably due to other omitted confounders. Income becomes insignificant in the fixed effects specifications. The unemployment rate also has a positive and significant effect on the probability of a cocaine mention; this is consistent with other studies that show increases in unemployment raise cocaine participation among hardcore users. Blacks are more likely and Hispanics are less likely to have a cocaine related ED episode compared to whites. College graduates are less likely to have an episode, consistent with the documented positive correlation between health and education. ${ }^{27}$ Individuals between the ages of 16 and 24 and between the ages of 25 and 54 are also less likely to have a cocaine related health emergency relative to older individuals. While cocaine use is more prevalent among adults and young adults, the positive marginal effect of ages over 54 implies that cocaine use may either have cumulative negative effects on health or perhaps older individuals, while they use less cocaine, are more susceptible to its

which reduced the costs of retailing and wholesaling. Costs also declined from a shift to low-cost labor as unemployed residents of urban ghettos replaced the professionals who dealt drugs during the 1970s and 1980s. See Grossman et al. $(1998,2002)$. 
detrimental effects. The sign of the sample response rate in DAWN is positive, as expected from equation (16), but it is not significant. The effect of the arrest rate for any drug possession is also imprecisely estimated. Specification 2 includes both year and MSA effects; here only changes in the price of cocaine within a given MSA are relied upon for identification. The estimated price elasticity is -0.26 . Since there are some MSA-year cells for which the arrest rate is missing, most subsequent specifications exclude them in order to maximize sample size. Specification 3 shows that the elasticity is not much affected $(-0.27)$ by this exclusion. The next two specifications add indicators of an MSA-specific linear trend. This is a very stringent test since only deviations around a linear trend, within each city, are used to identify the effects of each variable. The price effect remains significant at the one-percent level, and the elasticity decreases slightly in value to -0.19 . The addition of MSA-specific linear trends causes the MSA-level covariates to lose joint significance. Since these covariates are already controlling for trends within MSA's to a large extent, it is appropriate to draw inferences from the fixed-effects specifications that include these covariates, MSA indicators, and year indicators. The largest gain in adjusted R-square results from the addition of MSA effects; including MSA-linear trends raises the adjusted R-square by a relatively small amount. In subsequent analyses, fixed-effects specifications without city-specific trends are preferred and used to more reliably pin down the price elasticity.

Table 3 presents estimation of the baseline model given by equation (17) for the log of the odds of a heroin mention. The estimated price coefficients are negative and significant in all specifications. Specification 1 shows the effects of the MSA-level covariates. These are similar to those discussed with the cocaine models. The sample response rate has the correct positive sign and is significant. The arrest rate for drug possession is significant and positive in specification 1. This is likely the result of other unobserved city-level influences, since it becomes negative and insignificant in the fixed-effects specifications. Specification 2, which adds MSA effects, yields a

${ }^{27}$ See Grossman and Kaestner (1997). 
heroin price elasticity of -0.15 . Heroin remains significant at the one percent level even after the inclusion of city-specific linear trends, though the magnitude of the elasticity falls to -0.10 . Taking the estimate from specification 1 that includes all covariates and the year effects as the upper bound, the own-price elasticity of the probability of having a heroin related ED visit ranges from -0.15 to 0.34 , and is likely to be closer to the lower bound.

Table 4 estimates the model given by equation (21) by including the contemporaneous and one- and two-year lagged prices. The current prices are negative and significant in all specifications for both cocaine and heroin, including those with MSA-linear trends. For cocaine, the one- and two-year lagged prices are also negative and significant in the full fixed-effects models. Adding these lagged prices does not substantially reduce the magnitude of the current price elasticity for a cocaine mention. It is very similar to those from the baseline models, and ranges from -0.20 to 0.29 . The one-year lagged cocaine price elasticity is -0.21 , and the two-year lagged cocaine price elasticity is estimated at -0.15 . The effects of these lagged prices on the current probability of a cocaine related ED episode are negative and significant, and not much weaker than the effect of contemporaneous price. This is consistent with the addictive properties of cocaine and the ensuing positive intertemporal reinforcement effect. Since the dependent variable is a proxy for health, it is also possible that the addictive substance may have lagged effects on health. Thus, it may be reasonable to interpret the significantly negative lagged and current effects as saying that problematic cocaine use (due to lower prices) negatively affects current health and also has a cumulative detrimental effect on health which may not be realized until later. The coefficients of the contemporaneous and lagged prices can be used to calculate the long-run price elasticity of the probability of a cocaine mention, which measures the full current and future effects of a change in current price. It is about 2-3 times the magnitude of the short-run elasticity, ranging from -0.54 to 0.61 . 
The current price effect is also significantly negative in all models for logistic heroin mentions. The corresponding elasticity ranges from -0.14 to -0.26 . The range is tighter than before since the upper bound estimates obtained from the year-effects models are more in line with the other specifications. Thus, adding lagged prices makes some difference when MSA indicators are not there to capture some of their effect. The one and two-year lagged heroin price coefficients are also significantly negative in the fixed-effects model. The one-year lagged price elasticity is about -0.09 , and the two-year lagged price elasticity falls between -0.10 to -0.16 . Similar to the results with cocaine use, these tables show that the current heroin price elasticity is not substantially diminished with the inclusion of the lagged prices. The effects of past heroin prices on the current likelihood of a heroin related ED visit are also relatively substantial and of a similar magnitude to the effect of current price. The long-run elasticity ranges from -0.31 to -0.39 , about twice the magnitude of the short-run effect. This again suggests that drug use, especially heavy or chronic use, has cumulative ill-effects on health.

Table 5 provides a check for policy endogeneity. These models are similar to those discussed above except that they add one-year leading prices in addition to the current and lagged prices. Significantly negative lead price-effects may indirectly inform on the presence of policy endogeneity. All specifications include the one year lagging and leading own prices. ${ }^{28}$ The current price effect for both cocaine and heroin mentions is negative and significant in all fixed-effects specifications, even with MSA-specific trends. The contemporaneous price elasticity for a cocaine mention is estimated at around -0.16 to -0.23 . With respect to a heroin mention, the estimated price elasticity ranges from -0.17 to -0.23 . These magnitudes are highly similar to the estimates reported above and are not sensitive to the inclusion of the lead prices. The lagged-prices are significant in all fixed-effects specifications, while the lead prices are insignificant. The evidence does not point to the presence of policy endogeneity. The contemporaneous price elasticities

\footnotetext{
${ }^{28}$ Other leading and lagging structures yielded similar results.
} 
remain relatively robust to the inclusion of the leads, and current cocaine or heroin related ED episodes do not seem to be affected by future prices. These tables suggest that inferences based on the fixed-effects specifications are generally sound and robust.

Since policy endogeneity cannot definitively be ruled out, it would be reassuring if other specifications also confirm that it is not likely or that its effects do not substantially alter inferences. Note that the current price can be endogenous if it is a predetermined variable, for instance if past shocks to consumption outcomes affect future prices. If these unobserved shocks can be proxied to some extent and the price elasticities remain robust, one can have more confidence on these results. It was argued earlier that one set of factors that may affect past consumption as well as current prices is past drug enforcement efforts. Table 6 presents specifications that include lagged enforcement variables in order to control for any unobserved shocks to past drug-related outcomes and current prices. One set of lagged enforcement variables includes one-year lags of the arrest rate for any drug violation and the arrest rate for selling or trafficking in any drugs. The second set includes one-year lags of the arrest rate for any drug violation and the arrest rate for selling cocaine and opiates. The third set includes one-year lags of the arrest rate for any drug violation and the arrest rate for selling marijuana. The final set includes both one- and two-year lags of the arrest rate for any drug violation and the arrest rate for selling or trafficking in any drugs.

The top panel of Table 6 presents these results for cocaine mentions. Specifications 1-5 include MSA and year effects in addition to the other MSA-level covariates, and specifications 6-10 also add MSA-specific linear trends. The lagged enforcement variables as a group are generally significant. The cocaine price elasticity is significantly negative in all specifications and is robust to the inclusion of the lagged arrest rates. It decreases only marginally and ranges from -0.18 to -0.26 .

The bottom panel presents the same models for heroin mentions. Heroin price is negative and significant in all specifications, as are the lagged enforcement variables. The price elasticity diminishes slightly in magnitude, falling between -0.08 and -0.11 . These estimates are also highly 
similar to those obtained earlier from the baseline models and from those including lagged and lead prices. Overall, these two tables show that the elasticity for the probability of a cocaine or heroin related ED episode with respect to own-price is not sensitive to the addition of lagged arrest rates, which may be capturing to some extent unobserved shocks simultaneously affecting drug use and price. $^{29}$

All of the models presented thus far have included only the relevant drug's own price. Tables 7 through 9 estimate the cross-price models derived in equations (18) and (22). Table 7 presents the models for logistic drug episodes. This dependent variable measures the log of the odds ratio of the probability of any drug related ED episode. Since drug related emergency room visits can be induced by one or more illicit drugs, it is appropriate to include the price of both cocaine and heroin in these specifications. Cocaine is the most frequently mentioned illicit substance, present in about $29 \%$ of ED episodes for 2000 . Heroin and marijuana are the second most frequently cited, each mentioned in about $16 \%$ of the ED episodes. Specification (1) includes only contemporaneous cocaine and heroin prices based on (18), and specification (2) includes current and one-year lags of both drug prices, based on (22). These specifications are repeated with MSA fixed effects and MSA-linear trends. Current cocaine price is significantly negative in all models. The elasticity of the probability of a drug-related episode with respect to current cocaine price ranges from -0.15 to -0.29 . Current heroin price is negative in all specifications, but imprecisely estimated in the full fixed effects models. Its corresponding elasticity seems to have an upper bound of -0.10 . The one-year lagged cocaine price is significantly negative in all of the specifications; the elasticity lies between -0.12 and -0.17 . The elasticity with respect to the oneyear lagged heroin price is precisely estimated in the model with only year effects, at -0.07 . Overall, increases in the price of both drugs reduce the likelihood of a drug-related health

\footnotetext{
${ }^{29}$ The elasticities are more affected in the non-fixed effects models (not shown), suggesting that the full fixed effects and the city-specific trends are capturing much of the variation in such factors and other unobserved non-contemporaneous shocks.
} 
emergency, as proxied by an ED visit. The cocaine price elasticities are generally larger in magnitude than the heroin price elasticities; this may be due to the fact that cocaine is the most frequently cited in all drug-related episodes. Hence, the cocaine price would be expected to have a stronger effect. Past prices of both drugs, especially cocaine, also have a significantly negative effect on the likelihood of a drug-related ED visit, and the lagged price elasticities are not much smaller than the contemporaneous price elasticities. This is consistent with the results from the lagged-price models of cocaine and heroin mentions presented earlier. These results suggest that the negative health effects of cocaine and heroin use are positively related to current consumption and also positively related to the accumulated addictive stock.

Table 8 shows the results for logistic cocaine mentions. The current cocaine price is significant and negative in all specifications. Estimates of the current own-price elasticity lie between -0.22 and -0.31 . The one-year lagged cocaine price is significantly negative in all fixed effects specifications. The corresponding lagged own-price elasticity is estimated at around -0.22 . Note that these magnitudes are very similar to those estimated from models that exclude the cross prices. The current heroin price is negative and significant in the year-effects models but becomes imprecise with the addition of MSA indicators. The cross-price elasticity of cocaine mentions with respect to current heroin price seems to have an upper bound of -0.11 . While the negative sign suggests that cocaine and heroin are complements, caution must be exercised in such an interpretation. Since up to four drugs can be mentioned for any given ED drug episode, a cocaine mention does not indicate that only cocaine was used. In fact, for the year 2000 only $28 \%$ of cocaine mentions involved solely cocaine. Thus, a negative cross-price elasticity may not mean that a higher heroin price is decreasing cocaine use; it is possible that the higher heroin price is decreasing heroin use, which in turn may decrease heroin mentions, and this may be reflected in a decline of heroin mentions that also involved cocaine. Nevertheless, these cross-price elasticities do not contradict prior studies, which also suggest a complementary relationship between these two 
drugs (Saffer and Chaloupka, 1998; Dave, 2003). Lagged heroin price is negative but insignificant in all but one of the specifications.

Table 9 presents these cross-price models for the probability of a heroin mention. The current own-price elasticity is negative and significant in all models, and is estimated between -0.12 and -0.36 . The current price of cocaine is significant and negative in four of the six specifications, including those with city-level trends. Its corresponding elasticity lies between -0.34 and -0.52 . The relatively large magnitude of this elasticity may have to do with the fact that an ED drug episode can involve multiple mentions. Since more heroin users are polydrug users, the likelihood for multiple mentions is stronger for a heroin-related episode. For instance, data on arrestees, who are likely to be hardcore users, show that $69 \%$ of all heroin users also use cocaine, compared to only $15 \%$ of all cocaine users who use heroin. A larger cross-price elasticity of cocaine price with respect to a heroin mention may just be reflecting a larger own-price elasticity of cocaine price with respect to a cocaine mention for those heroin mentions that also involve cocaine. Lagged heroin price is significantly negative in the full fixed effects specification and has an elasticity of about 0.08. Lagged cocaine price is significant in the specification with MSA and year effects and MSAlinear trends, with an elasticity of -0.30 . Though the caveat with respect to multiple mentions applies, these results are consistent with Dave (2003), which suggested that cocaine and heroin are both current and intertemporal complements. The significance and negative sign of the lagged price effects implies that the accumulated addictive stock, and not just current consumption, also has a negative effect on current healthy outcomes. These lagged negative cross-price elasticities are also consistent with a positive cross-reinforcement effect. That is, higher past heroin prices may reduce past heroin use, which may depress current cocaine use and thus reduce the number of cocaine related ED visits.

\section{Conclusions}


The objective of this study was to estimate the empirical relationship between the prices of cocaine and heroin and objective indicators of their use. By employing data on drug related hospital emergency department episodes, this study bypasses any measurement errors prevalent in survey data due to misreporting. The persons sampled in DAWN constitute an important subgroup of hardcore drug users, which is often not captured by national surveys. Since these persons are more likely to be serious users, impose the heaviest costs on society, and are the targets of much illegal drug policy, studying outcomes related to their addictive consumption behavior is very important from a public policy stance.

The key conclusion that emerges from this study is that cocaine and heroin prices have a significantly negative effect on the probability of a cocaine or heroin related ED episode. Results indicate that the elasticity of the probability of a cocaine mention with respect to own price is about -0.27 , and the own-price elasticity of the probability of a heroin mention is about -0.15 . These elasticities are robust to various specification checks and controls for unobservables and policy endogeneity. Prices of both cocaine and heroin have a significantly negative effect on serious cocaine and heroin related health problems. The results show the presence of significantly negative own and cross-price effects but insignificant lead-price effects.

Serious drug-related health problems as proxied by ED visits are more likely correlated with hardcore or heavy drug use than with casual use. Dave (2003) used objective drug use indicators based on urinalysis from the Drug Use Forecasting system to estimate cocaine and heroin participation elasticities for hardcore users of -0.23 and -0.08 respectively. These can be used to obtain crude estimates of the structural elasticity of the probability of drug-related ED visits with respect to the probability of drug use for hardcore users: 1.17 for cocaine and 1.88 for heroin. ${ }^{30}$

\footnotetext{
${ }^{30}$ While these structural elasticities indicate a strong correlation between heavy drug use and drugrelated ED visits, they should be interpreted with care since they do not account for the level or intensity of consumption.
} 
The analyses from DAWN indicate that drug prices directly affect the "bottom line", that is higher prices improve health outcomes. The contemporaneous elasticity understates the full effect by a magnitude of about one-half. Strong negative lagged price effects show that higher drug prices improve health outcomes in current and future periods. In a fixed population, the elasticity estimates from this study imply that a $10 \%$ increase in the current price of cocaine in an MSA will prevent about 91 cocaine-related ED visits this year and an additional 159 ED visits over the next two years. A corresponding increase in heroin price will prevent about 32 heroin-related ED visits this year and an additional 44 ED visits subsequently. ${ }^{31}$ Since studies ( Kuziemko and Levitt, 2001; Grossman et al., 1998) have shown that drug prices are positively related to enforcement efforts, they represent a tool by which the public sector can exercise control over the market for illicit, addictive, unhealthy substances and related outcomes.

\footnotetext{
${ }^{31}$ These estimates are based on Table 4. If the cross-price effects are negative, then more drugrelated ED visits will be prevented.
} 


\section{References}

T.W. Anderson, and C. Hsiao, "Estimation of Dynamic Models with Error Components," Journal of the American Statistical Association 76, (1981): 598-606.

T.W. Anderson, and C. Hsiao, "Formulation and Estimation of Dynamic Models Using Panel Data," Journal of Econometrics 18, (1982): 47-82.

B.H. Baltagi, Econometric Analysis of Panel Data (New York: John A. Wiley \& Sons, 1995).

B.H. Baltagi, J.M. Griffin, and W. Xiong, "To Pool or not to Pool: Homogeneous Versus Heterogeneous Estimators Applied to Cigarette Demand," The Review of Economics and Statistics $82,(2000)$ 117-126.

B.H. Baltagi, and D. Levin, "Estimating Dynamic Demand for Cigarettes Using Panel Data: The Effects of Bootlegging, Taxation, and Advertising Reconsidered," The Review of Economics and Statistics 68, 1(1986): 148-155.

S. Basov, M. Jacobson, and J.A. Miron, "Prohibition and the Market for Illegal Drugs: An Overview of Recent History," Working Paper (Boston: Boston University, 2001).

G.S. Becker, "Crime and Punishment: An Economic Approach," Journal of Political Economy 76, no. 2 (1968): 169-217.

G.S. Becker and K.M. Murphy, "A Theory of Rational Addiction," Journal of Political Economy 96, no.4 (1988): 675-700.

G.S. Becker, M. Grossman, and K.M. Murphy, "An Empirical Analysis of Cigarette Addiction," American Economic Review 84, no. 3 (1994): 396-418.

G.S. Becker, M. Grossman, and K.M. Murphy, "The Economic Theory of Illegal Goods: The Case of Drugs," Working Paper, (2003).

A. Bretteville-Jensen and M. Sutton, "The Income Generating Behavior of Injecting Drug Users in Oslo," Addiction 91(1), (1996):63-79.

Bureau of Census website: www.census.gov.

Bureau of Economic Analysis website: www.bea.gov.

Bureau of Labor Statistics website: www.bls.gov.

Bureau of Justice Statistics, U.S. Department of Justice, Sourcebook of Criminal Justice Statistics 2000 (Washington: U.S. Government Printing Office, 2001).

J.P. Caulkins, "Drug Prices and Emergency Department Mentions for Cocaine and Heroin," American Journal of Public Health 91, no. 9 (2001): 1446-1448.

J.P. Caulkins, "Estimating Elasticities of Demand for Cocaine and Heroin with DUF Data," Working Paper( Pittsburgh: Heinz School of Public Policy, Carnegie Mellon University, 1996). 
J.P. Caulkins, “Developing Price Series for Cocaine,” Working Paper (RAND: 1994).

J.P. Chaiken and N.Chaiken, Analysis of the Drug Use Forecasting Sample of Adult Arrestees. Draft Report to the National Institute of Justice. Washington, D.C.: Abt Associates.

F.J. Chaloupka, M. Grossman, and J.A. Tauras, "The Demand for Cocaine and Marijuana by Youth," in The Economic Analysis of Substance Use and Abuse: An Integration of Econometric and Behavioral Economic Research, ed. F.J. Chaloupka, M. Grossman, W.K. Bickel, and H. Saffer (Chicago: University of Chicago Press, 1999): 133-155.

A. Clark, "The Economics of Drug Legalization," Working Paper (Orleans, France: University of Orleans, 1998).

B.D. Crane, A.R. Rivolo, and G.C. Comfort, An Empirical Examination of Counterdrug Interdiction Program Effectiveness (Alexandria, Virginia: Institute for Defense Analysis, 1997).

D. Dave, “Illicit Drug Use among Arrestees and Drug Prices,” Working Paper, 2003.

J. DeSimone, “Is Marijuana a Gateway Drug?," Eastern Economics Journal 24, no. 2 (1998): 149164.

J. DeSimone, "The Effect of Cocaine and Heroin Prices and Arrests on Cocaine and HeroinRelated Deaths," Working Paper, (2001).

J. DeSimone, "The Response of Drug Injection and Needle Sharing to Local Cocaine and Heroin Prices, AIDS Prevalence, and Needle Exchange Programs,” Working Paper, (2002).

J. DeSimone and M.J. Farrelly, "Price and Enforcement Effects on Cocaine and Marijuana Demand," Working Paper (Greenville, North Carolina: East Carolina University, 2001).

M.J. Farrelly, J.W. Bray, G.A. Zarkin, and B.W. Wendling, "The Joint Demand for Cigarettes and Marijuana: Evidence from the National Household Surveys on Drug Abuse," Journal of Health Economics 20, no. 1 (2001): 51-68.

M. Grossman and R. Kaestner, "Effects of Education on Health." In The Social Benefits of Education, edited by J. Behrman and N. Stacey. Ann Arbor, Michigan: University of Michigan Press, 1997.

M. Grossman and F.J. Chaloupka, "The Demand for Cocaine by Young Adults: A Rational Addiction Approach," Journal of Health Economics 17, no. 4 (1998): 427-474.

M. Grossman, F.J. Chaloupka, and K. Shim, "Illegal Drug Use and Public Policy," Health Affairs 21, (2002): 134-144.

J. Gruber and B. Köszegi, “Is Addiction 'Rational'? Theory and Evidence," Quarterly Journal of Economics 116, no. 4 (2001): 1261-1303. 
H. Harwood, D. Fountain, and G. Livermore, The Economic Costs of Alcohol and Drug Abuse in the United States, 1992 (Rockville, MD: National Institutes of Health, 1998).

J.A. Hausman, "Specification Tests in Econometrics," Econometrica 46, no. 6 (1978): 1251-1271.

J.L. Horowitz, "Should the DEA's STRIDE Data be Used for Economic Analyses of Markets for Illegal Drugs," Journal of the American Statistical Association 96, (2001): 1254-1271.

D. Hunt and W. Rhodes, Methodology Guide for ADAM, Washington D.C.:National Institute of Justice, 2001.

R.R. Hyatt, Jr. and W. Rhodes, "The Price and Purity of Cocaine: The Relationship to Emergency Room Visits and Death, and to Drug Use among Arrestees," Statistics in Medicine 14, (1995): 655668.

I. Kuziemko and S. Levitt, “An Empirical Analysis of Imprisoning Drug Offenders,” Working Paper (Chicago: University of Chicago, 2001).

L.W. Lee, “Would Harassing Drug Users Work?” Journal of Political Economy 101, no. 5 (1993): 939-959.

R. MacCoun and P. Reuter, Drug War Heresies: Learning from Other Vices, Times, and Places (Cambridge, U.K.: Cambridge University Press, 2001).

C.F. Manski, J.V. Pepper, and C.V. Petrie, eds., Informing America's Policy on Illegal Drugs: What We Don't Know Keeps Hurting Us, Committee on Data and Research for Policy on Illegal Drugs, National Research Council (Washington, DC: National Academy Press, 2001).

J.A. Miron, "The Effect of Drug Prohibition on Drug Prices,” Working Paper (Boston: Boston University and Bastiat Institute, 2001).

K.E. Model, "The Effect of Marijuana Decriminalization on Hospital Emergency Room Drug Episodes: 1975-1978," Journal of the American Statistical Association 88, no. 423 (1993): 737-747.

Office of National Drug Control Policy, Drug Policy Information Clearing House Fact Sheet (Washington, DC: Office of National Drug Control Policy, March, 2003).

Office of National Drug Control Policy, The National Drug Control Strategy: 2001 Annual Report (Washington, DC: Office of National Drug Control Policy, 2001).

Office of National Drug Control Policy, What America's Users Spend on Illegal Drugs, 1988-1998 (Washington, DC: Office of National Drug Control Policy, 2000).

R.L. Pacula, M. Grossman, F.J. Chaloupka, P.M. O’Malley, L.D. Johnston, and M.C. Farrelly, "Marijuana and Youth," in Risky Behavior among Youths: An Economic Analysis, ed. J. Gruber (Chicago: University of Chicago Press, 2000): 271-326.

W. Rhodes, R. Hyatt, and P. Scheiman, "The Price of Cocaine, Heroin, and Marijuana, 1981-1993," The Journal of Drug Issues 24, (1994): 383-402. 
W. Rhodes, P. Johnston, S. Han, Q. McMullen, and L. Hozik, "Illicit Drugs: Price Elasticity of Demand and Supply," ABT Associates, (2001).

J. Roumasset and J. Hadreas, "Addicts, Fences and the Market for Stolen Goods," Public Finance Quarterly, (1977).

H. Saffer and F.J. Chaloupka, “The Demand for Illicit Drugs,” Economic Inquiry 37, no. 3, (1999a): 401-411.

H. Saffer and F.J. Chaloupka, "Demographic Differentials in the Demand for Alcohol and Illicit Drugs," in The Economic Analysis of Substance Use and Abuse, eds. F.J. Chaloupka, M. Grossman, W.K. Bickel, and H. Saffer (Chicago: University of Chicago Press, 1999): 187-212.

L.P. Silverman and N.L. Spruill, "Urban Crime and Price of Heroin,” Urban Economics 4, (1977): 80-103.

C.F. Thies and C.A. Register, "Decriminalization of Marijuana and the Demand for Alcohol, Marijuana and Cocaine," Social Science Journal 30, no. 4 (1993): 385-399.

J.C. van Ours, "The Price Elasticity of Hard Drugs: The Case of Opium in the Dutch East Indies, 1923-1938," Journal of Political Economy 103, (1995):261-279. 
Table 1

\section{Sample Means}

\begin{tabular}{|c|c|c|}
\hline Variable & Definition & Mean \\
\hline Drug Episode Rate & $\begin{array}{l}\text { Total drug related emergency department episodes in each MSA divided by MSA } \\
\text { population }\end{array}$ & $\begin{array}{r}0.00312 \\
(0.00130)\end{array}$ \\
\hline $\begin{array}{l}\text { Logistic Drug } \\
\text { Episodes }\end{array}$ & Log of the odds of drug episode rate & $\begin{array}{r}-5.84686 \\
(0.39722)\end{array}$ \\
\hline Cocaine Mention Rate & $\begin{array}{l}\text { Total number of times cocaine was mentioned in the emergency department drug } \\
\text { episodes in each MSA divided by MSA population }\end{array}$ & $\begin{array}{r}0.00118 \\
(0.00074)\end{array}$ \\
\hline $\begin{array}{l}\text { Logistic Cocaine } \\
\text { Mentions }\end{array}$ & Log of the odds of cocaine mention rate & $\begin{array}{l}-6.96593 \\
(0.71745)\end{array}$ \\
\hline Heroin Mention Rate & $\begin{array}{l}\text { Total number of times heroin was mentioned in the emergency department drug } \\
\text { episodes in each MSA divided by MSA population }\end{array}$ & $\begin{array}{r}0.00064 \\
(0.00070)\end{array}$ \\
\hline $\begin{array}{l}\text { Logistic Heroin } \\
\text { Mentions }\end{array}$ & Log of the odds of heroin mention rate & $\begin{array}{r}-7.91555 \\
(1.11526)\end{array}$ \\
\hline Cocaine Price & $\begin{array}{l}\text { Price of one pure gram of cocaine, based on all purchases, divided by the annual } \\
\text { national consumer price index }\end{array}$ & $\begin{array}{r}80.69862 \\
(24.78975)\end{array}$ \\
\hline Heroin Price & $\begin{array}{l}\text { Price of one pure gram of heroin, based on all purchases, divided by the annual } \\
\text { national consumer price index }\end{array}$ & $\begin{array}{r}451.07930 \\
(387.55420) \\
\end{array}$ \\
\hline Personal Income & $\begin{array}{l}\text { Per capita personal income in each MSA, divided by the annual national consumer } \\
\text { price index }\end{array}$ & $\begin{array}{r}18211.73 \\
(3170.00) \\
\end{array}$ \\
\hline Unemployment & Unemployment rate in each MSA & $\begin{array}{r}0.05210 \\
(0.01764) \\
\end{array}$ \\
\hline Male & Percent of MSA population that are male & $\begin{array}{r}0.47763 \\
(0.01874)\end{array}$ \\
\hline Black & Percent of MSA population that are black & $\begin{array}{r}0.15666 \\
(0.10028) \\
\end{array}$ \\
\hline Other & Percent of MSA population that are of a race other than white or black & $\begin{array}{r}0.05510 \\
(0.04955)\end{array}$ \\
\hline Hispanic & Percent of MSA population that are Hispanic & $\begin{array}{r}0.12228 \\
(0.14198)\end{array}$ \\
\hline Age $16-24$ & Percent of MSA population that are aged 16 to 24 & $\begin{array}{r}0.16254 \\
(0.02110) \\
\end{array}$ \\
\hline Age $25-54$ & Percent of MSA population that are aged 25 to 54 & $\begin{array}{r}0.59057 \\
(0.03876) \\
\end{array}$ \\
\hline High School & Percent of MSA population that are high school graduates & $\begin{array}{r}0.80013 \\
(0.05517) \\
\end{array}$ \\
\hline College & Percent of MSA population that are college graduates & $\begin{array}{r}0.25992 \\
(0.05852)\end{array}$ \\
\hline Response Rate & Responding sample hospitals as a fraction of total eligible hospitals & $\begin{array}{r}0.57047 \\
(0.16351) \\
\end{array}$ \\
\hline Log Response Rate & Log of response rate & $\begin{array}{r}-0.60215 \\
(0.28718) \\
\end{array}$ \\
\hline $\begin{array}{l}\text { Drug Possession } \\
\text { Arrest Rate }\end{array}$ & $\begin{array}{l}\text { Total number of arrests in each MSA due to any drug possession divided by MSA } \\
\text { population }\end{array}$ & $\begin{array}{r}0.00388 \\
(0.00217)\end{array}$ \\
\hline $\begin{array}{l}\text { Drug Violation Arrest } \\
\text { Rate }\end{array}$ & $\begin{array}{l}\text { Total number of arrests in each MSA due to any drug violation divided by MSA } \\
\text { population }\end{array}$ & $\begin{array}{r}0.00588 \\
(0.00295) \\
\end{array}$ \\
\hline Drug Sale Arrest Rate & $\begin{array}{l}\text { Total number of arrests in each MSA due to any drug sale or trafficking divided by } \\
\text { MSA population }\end{array}$ & $\begin{array}{r}0.00171 \\
(0.00138) \\
\end{array}$ \\
\hline $\begin{array}{l}\text { Cocaine Sale Arrest } \\
\text { Rate }\end{array}$ & $\begin{array}{l}\text { Total number of arrests in each MSA due to cocaine sale or trafficking divided by } \\
\text { MSA population }\end{array}$ & $\begin{array}{r}0.00108 \\
(0.00119) \\
\end{array}$ \\
\hline $\begin{array}{l}\text { Marijuana Sale Arrest } \\
\text { Rate }\end{array}$ & $\begin{array}{l}\text { Total number of arrests in each MSA due to marijuana sale or trafficking divided by } \\
\text { MSA population }\end{array}$ & $\begin{array}{r}0.00033 \\
(0.00027)\end{array}$ \\
\hline Population & Total MSA Population & $\begin{array}{r}3732931 \\
(2363680) \\
\end{array}$ \\
\hline \multicolumn{2}{|l|}{ Observations } & 252 \\
\hline
\end{tabular}

Notes: Standard deviations are in parentheses. Number of observations listed represents the maximum number.

For some variables, the actual sample size is slightly less due to missing information. 
Table 2

Logistic Cocaine Mentions

Baseline Models

\begin{tabular}{|c|c|c|c|c|c|}
\hline Specification & 1 & 2 & 3 & 4 & 5 \\
\hline Cocaine Price & $\begin{array}{c}-0.00310 * * \\
(-1.95) \\
\varepsilon=-0.250\end{array}$ & $\begin{array}{c}-0.00324 * * * \\
(-2.95) \\
\varepsilon=-0.261\end{array}$ & $\begin{array}{c}-0.00335 * * * \\
(-3.31) \\
\varepsilon=-0.270\end{array}$ & $\begin{array}{c}-0.00241 * * * \\
(-2.40) \\
\varepsilon=-0.194\end{array}$ & $\begin{array}{c}-0.00226^{* * *} \\
(-2.37) \\
\varepsilon=-0.182\end{array}$ \\
\hline Personal Income & $\begin{array}{c}0.00006 * * * \\
(3.70)\end{array}$ & \multirow{11}{*}{ Yes** } & \multirow{11}{*}{ Yes*** } & \multirow{11}{*}{ Yes } & \multirow{11}{*}{ Yes } \\
\hline Unemployment & $\begin{array}{c}0.11597 * * * \\
(3.63)\end{array}$ & & & & \\
\hline Male & $\begin{array}{c}-1.49445 \\
(-0.79)\end{array}$ & & & & \\
\hline Black & $\begin{array}{c}2.77521 * * * \\
(6.03)\end{array}$ & & & & \\
\hline Other & $\begin{array}{c}1.46131 \\
(1.34)\end{array}$ & & & & \\
\hline Hispanic & $\begin{array}{c}-2.37167 * * * \\
(-4.92)\end{array}$ & & & & \\
\hline Age $16-24$ & $\begin{array}{c}-7.65840 * * * \\
(-4.54)\end{array}$ & & & & \\
\hline Age 25 - 54 & $\begin{array}{c}-2.38602 * * * \\
(-2.13) \\
\end{array}$ & & & & \\
\hline $\begin{array}{l}\text { High School } \\
\text { Graduate }\end{array}$ & $\begin{array}{c}-0.42395 \\
(-0.30)\end{array}$ & & & & \\
\hline College Graduate & $\begin{array}{c}-3.14793 * * * \\
(-3.63) \\
\end{array}$ & & & & \\
\hline Log Response Rate & $\begin{array}{c}0.15878 \\
(1.36) \\
\end{array}$ & & & & \\
\hline $\begin{array}{l}\text { Drug Possession } \\
\text { Arrest Rate }\end{array}$ & $\begin{array}{c}-6.84913 \\
(-0.39)\end{array}$ & $\begin{array}{c}-17.42437 \\
(-1.19)\end{array}$ & - & $\begin{array}{c}-2.31625 \\
(-0.12)\end{array}$ & - \\
\hline Year Effects & Yes & Yes*** & Yes*** & Yes*** & Yes*** \\
\hline MSA Effects & No & Yes*** & Yes*** & Yes*** & Yes*** \\
\hline MSA-Linear Trend & No & No & No & Yes*** & Yes*** \\
\hline R-Squared & 0.631 & 0.885 & 0.875 & 0.929 & 0.929 \\
\hline Observations & 238 & 238 & 251 & 238 & 251 \\
\hline
\end{tabular}

Notes: All estimates are from weighted regressions. Dependent variable is $\log (\mathrm{A} / 1-\mathrm{A})$ where $\mathrm{A}$ is the total number of cocaine mentions in each MSA divided by population. T-ratios are in parentheses. $* * *$ significant at 1 percent $* *$ significant at 5 percent $*$ significant at 10 percent. Elasticities are reported where the own-price coefficient is significant at 10 percent or less in a one-tailed test. 
Table 3

Logistic Heroin Mentions

Baseline Models

\begin{tabular}{|c|c|c|c|c|c|}
\hline Specification & 1 & 2 & 3 & 4 & 5 \\
\hline Heroin Price & $\begin{array}{c}-0.00075 * * * \\
(-3.51) \\
\varepsilon=-0.338\end{array}$ & $\begin{array}{c}-0.00032 * * * \\
(-2.88) \\
\varepsilon=-0.144\end{array}$ & $\begin{array}{c}-0.00033 * * * \\
(-2.70) \\
\varepsilon=-0.149\end{array}$ & $\begin{array}{c}-0.00021 * * \\
(-2.08) \\
\varepsilon=-0.095\end{array}$ & $\begin{array}{c}-0.00023 * * * \\
(-2.40) \\
\varepsilon=-0.104\end{array}$ \\
\hline Personal Income & $\begin{array}{c}0.00014 * * * \\
(6.85)\end{array}$ & \multirow{11}{*}{ Yes*** } & \multirow{11}{*}{ Yes*** } & \multirow{11}{*}{ Yes } & \multirow{11}{*}{ Yes** } \\
\hline Unemployment & $\begin{array}{c}0.24796^{* * * *} \\
(5.66)\end{array}$ & & & & \\
\hline Male & $\begin{array}{c}2.25921 \\
(0.85)\end{array}$ & & & & \\
\hline Black & $\begin{array}{c}1.09963^{*} \\
(1.68)\end{array}$ & & & & \\
\hline Other & $\begin{array}{c}1.33243 \\
(1.05)\end{array}$ & & & & \\
\hline Hispanic & $\begin{array}{c}-4.41750 * * * \\
(-5.87)\end{array}$ & & & & \\
\hline Age $16-24$ & $\begin{array}{c}-4.75061 * * \\
(-1.99)\end{array}$ & & & & \\
\hline Age $25-54$ & $\begin{array}{c}-3.58345^{* *} \\
(-2.22)\end{array}$ & & & & \\
\hline $\begin{array}{l}\text { High School } \\
\text { Graduate }\end{array}$ & $\begin{array}{c}-2.95770 \\
(-1.56)\end{array}$ & & & & \\
\hline College Graduate & $\begin{array}{c}0.60877 \\
(0.54)\end{array}$ & & & & \\
\hline Log Response Rate & $\begin{array}{c}1.04361^{* * * *} \\
(6.49)\end{array}$ & & & & \\
\hline $\begin{array}{l}\text { Drug Possession } \\
\text { Arrest Rate }\end{array}$ & $\begin{array}{c}56.62310 * * * \\
(2.41)\end{array}$ & $\begin{array}{c}-2.07989 \\
(-0.15)\end{array}$ & - & $\begin{array}{c}-29.01166 \\
(-1.46)\end{array}$ & - \\
\hline Year Effects & Yes*** & Yes*** & Yes*** & Yes*** & Yes*** \\
\hline MSA Effects & No & Yes*** & Yes*** & Yes*** & Yes*** \\
\hline MSA-Linear Trend & No & No & No & Yes*** & Yes*** \\
\hline R-Squared & 0.695 & 0.943 & 0.923 & 0.960 & 0.960 \\
\hline Observations & 233 & 233 & 246 & 233 & 246 \\
\hline
\end{tabular}

Notes: All estimates are from weighted regressions. Dependent variable is $\log (\mathrm{A} / 1-\mathrm{A})$ where A is the total number of heroin mentions in each MSA divided by population. T-ratios are in parentheses. $* * *$ significant at 1 percent $* *$ significant at 5 percent $*$ significant at 10 percent. Elasticities are reported where the own-price coefficient is significant at 10 percent or less in a one-tailed test. 
Table 4

Logistic Cocaine \& Heroin Mentions Lagged Prices

\begin{tabular}{|c|c|c|c|c|c|c|}
\hline Dependent Variable & \multicolumn{3}{|c|}{ Logistic Cocaine Mentions } & \multicolumn{3}{|c|}{ Logistic Heroin Mentions } \\
\hline Specification & 1 & 2 & 3 & 1 & 2 & 3 \\
\hline Own Price & $\begin{array}{c}-0.00364 * * \\
(-2.02) \\
\varepsilon=-0.293\end{array}$ & $\begin{array}{c}-0.00246 * * * \\
(-2.40) \\
\varepsilon=-0.198\end{array}$ & $\begin{array}{c}-0.00280 * * * \\
(-2.99) \\
\varepsilon=-0.226\end{array}$ & $\begin{array}{c}-0.00057 * * * \\
(-2.53) \\
\varepsilon=-0.257\end{array}$ & $\begin{array}{c}-0.00031 * * * \\
(-2.81) \\
\varepsilon=-0.140\end{array}$ & $\begin{array}{c}-0.00027 * * * \\
(-2.58) \\
\varepsilon=-0.122\end{array}$ \\
\hline $\begin{array}{l}1 \text { Year Lagged } \\
\text { Own Price }\end{array}$ & $\begin{array}{c}-0.00223 \\
(-1.26)\end{array}$ & $\begin{array}{c}-0.00253 * * * \\
(-2.61) \\
\varepsilon=-0.206\end{array}$ & $\begin{array}{c}-0.00258 * * * \\
(-3.05) \\
\varepsilon=-0.210\end{array}$ & $\begin{array}{c}-0.00026 \\
(-1.24)\end{array}$ & $\begin{array}{c}-0.00018 * * \\
(-1.64) \\
\varepsilon=-0.088\end{array}$ & $\begin{array}{c}-0.00011 \\
(-1.19)\end{array}$ \\
\hline $\begin{array}{l}2 \text { Year Lagged } \\
\text { Own Price }\end{array}$ & $\begin{array}{c}-0.00048 \\
(-0.30)\end{array}$ & $\begin{array}{c}-0.00173 * * \\
(-1.92) \\
\varepsilon=-0.145\end{array}$ & $\begin{array}{c}-0.00216 * * * \\
(-2.96) \\
\varepsilon=-0.181 \\
\end{array}$ & $\begin{array}{c}-0.00030^{*} \\
(-1.54) \\
\varepsilon=-0.161\end{array}$ & $\begin{array}{c}-0.00019 * * \\
(-2.08) \\
\varepsilon=-0.102\end{array}$ & $\begin{array}{c}-0.00012^{*} \\
(-1.36) \\
\varepsilon=-0.065\end{array}$ \\
\hline Long Run Elasticity & $\varepsilon=-0.293$ & $\varepsilon=-0.542$ & $\varepsilon=-0.608$ & $\varepsilon=-0.392$ & $\varepsilon=-0.307$ & $\varepsilon=-0.176$ \\
\hline $\begin{array}{l}\text { MSA Socioeconomic } \\
\text { Covariates }\end{array}$ & Yes*** & Yes*** & Yes** & Yes*** & Yes*** & Yes \\
\hline Year Effects & Yes & Yes*** & Yes*** & Yes** & Yes*** & Yes*** \\
\hline MSA Effects & No & $\mathrm{Yes}^{* * *}$ & Yes*** & No & Yes*** & Yes*** \\
\hline MSA-Linear Trend & No & No & Yes*** & No & No & Yes*** \\
\hline R-Squared & 0.553 & 0.879 & 0.934 & 0.700 & 0.945 & 0.961 \\
\hline Observations & 249 & 249 & 249 & 242 & 242 & 242 \\
\hline
\end{tabular}

Notes: All estimates are from weighted regressions. Dependent variable is $\log (\mathrm{A} / 1-\mathrm{A})$ where A is the total number of cocaine or heroin mentions in each MSA divided by population. Own price refers to cocaine price in the logistic cocaine mention models, and heroin price in the logistic heroin mention models. T-ratios are in parentheses. $* * *$ significant at 1 percent $* *$ significant at 5 percent $*$ significant at 10 percent. MSA socioeconomic covariates include: personal income, unemployment, male, black, other, Hispanic, age 16-24, age 25-54, high school graduate, college graduate, and log response rate. Elasticities are reported where the own-price coefficient is significant at 10 percent or less in a one-tailed test. 
Table 5

Logistic Cocaine and Heroin Mentions Lagged \& Leading Prices

\begin{tabular}{|l|c|c|c|c|c|c|}
\hline Dependent Variable & \multicolumn{3}{|c|}{ Logistic Cocaine Mentions } & \multicolumn{3}{c|}{ Logistic Heroin Mentions } \\
\hline Specification & 1 & 2 & 3 & 4 & 5 & 6 \\
\hline Own Price & $\begin{array}{c}-0.00068 \\
(-0.38)\end{array}$ & $\begin{array}{c}-0.00197 * * \\
(-1.81) \\
\varepsilon=-0.161\end{array}$ & $\begin{array}{c}-0.00279 * * * \\
(-2.62) \\
\varepsilon=-0.226\end{array}$ & $\begin{array}{c}-0.00050^{* * *} \\
(-2.23) \\
\varepsilon=-0.225\end{array}$ & $\begin{array}{c}-0.00037^{* * *} \\
(-3.54) \\
\varepsilon=-0.167\end{array}$ & $\begin{array}{c}-0.00027 * * * \\
(-2.63) \\
\varepsilon=-0.122\end{array}$ \\
\hline $\begin{array}{l}\text { 1 Year Leading } \\
\text { Own Price }\end{array}$ & Yes & Yes & Yes & Yes* & Yes & Yes \\
\hline $\begin{array}{l}\text { 1 Year Lagged } \\
\text { Own Price }\end{array}$ & Yes & Yes** & Yes*** & Yes* & Yes** & Yes \\
\hline $\begin{array}{l}\text { MSA Socioeconomic } \\
\text { Covariates }\end{array}$ & Yes*** & Yes** & Yes & Yes*** & Yes** & Yes \\
\hline Year Effects & Yes & Yes*** & Yes*** & Yes*** & Yes*** & Yes*** \\
\hline MSA Effects & No & Yes*** & Yes*** & No & Yes*** & Yes*** \\
\hline MSA-Linear Trend & No & No & Yes*** & No & No & Yes*** \\
\hline R-Squared & 0.657 & 0.901 & 0.933 & 0.720 & 0.952 & 0.966 \\
\hline Observations & 217 & 217 & 217 & 211 & 211 & 211 \\
\hline
\end{tabular}

Notes: All estimates are from weighted regressions. Dependent variable is $\log (\mathrm{A} / 1-\mathrm{A})$ where $\mathrm{A}$ is the total number of cocaine or heroin mentions in each MSA divided by population. T-ratios are in parentheses. $* * *$ significant at 1 percent $* *$ significant at 5 percent $*$ significant at 10 percent. MSA socioeconomic covariates include: personal income, unemployment, male, black, other, Hispanic, age 16-24, age 25-54, high school graduate, college graduate, and log response rate. Elasticities are reported where the own-price coefficient is significant at 10 percent or less in a one-tailed test. 
Table 6

Logistic Cocaine and Heroin Mentions

With Lagged Enforcement Measures

\begin{tabular}{|c|c|c|c|c|c|c|c|c|c|c|}
\hline Specification & 1 & 2 & 3 & 4 & 5 & 6 & 7 & 8 & 9 & 10 \\
\hline \multicolumn{11}{|c|}{ Logistic Cocaine Mentions } \\
\hline $\begin{array}{l}\text { Cocaine } \\
\text { Price }\end{array}$ & $\begin{array}{c}-0.00334 * * * \\
(-3.30) \\
\varepsilon=-0.273\end{array}$ & $\begin{array}{c}-0.00313 * * * \\
(-2.99) \\
\varepsilon=-0.256\end{array}$ & $\begin{array}{c}-0.00271 * * * \\
(-2.44) \\
\varepsilon=-0.221\end{array}$ & $\begin{array}{c}-0.00268 * * * \\
(-2.37) \\
\varepsilon=-0.219\end{array}$ & $\begin{array}{c}-0.00273 * * * \\
(-2.47) \\
\varepsilon=-0.223\end{array}$ & $\begin{array}{c}-0.00243 * * * \\
(-2.49) \\
\varepsilon=-0.198\end{array}$ & $\begin{array}{c}-0.00243 * * * \\
(-2.52) \\
\varepsilon=-0.198\end{array}$ & $\begin{array}{c}-0.00222 * * \\
(-2.30) \\
\varepsilon=-0.181\end{array}$ & $\begin{array}{c}-0.00242 * * * \\
(-2.44) \\
\varepsilon=-0.198\end{array}$ & $\begin{array}{c}-0.00247 * * * \\
(-2.48) \\
\varepsilon=-0.202\end{array}$ \\
\hline $\begin{array}{l}\text { MSA SES } \\
\text { Covariates }\end{array}$ & Yes*** & Yes* & Yes* & Yes* & Yes** & Yes & Yes & Yes & Yes & Yes \\
\hline $\begin{array}{l}\text { Lagged } \\
\text { Enforcement }\end{array}$ & No & Group 1 & Group 2* & Group3 & Group 4* & No & Group 1* & Group 2*** & Group3** & Group 4* \\
\hline Year Effects & Yes*** & Yes*** & Yes*** & Yes*** & Yes*** & Yes*** & Yes* & Yes*** & Yes*** & Yes*** \\
\hline MSA Effects & Yes*** & Yes*** & Yes*** & Yes*** & Yes*** & Yes*** & Yes*** & Yes*** & Yes*** & Yes*** \\
\hline $\begin{array}{l}\text { MSA-Linear } \\
\text { Trend }\end{array}$ & No & No & No & No & No & Yes*** & Yes*** & Yes*** & Yes*** & Yes*** \\
\hline R-Squared & 0.884 & 0.885 & 0.889 & 0.888 & 0.888 & 0.930 & 0.932 & 0.936 & 0.932 & 0.932 \\
\hline Observations & 238 & 239 & 237 & 237 & 238 & 238 & 239 & 237 & 237 & 238 \\
\hline \multicolumn{11}{|c|}{ Logistic Heroin Mentions } \\
\hline $\begin{array}{l}\text { Heroin } \\
\text { Price }\end{array}$ & $\begin{array}{c}-0.00028 * * * \\
(-2.46) \\
\varepsilon=-0.129\end{array}$ & $\begin{array}{c}-0.00022 * * \\
(-2.08) \\
\varepsilon=-0.101\end{array}$ & $\begin{array}{c}-0.00018 * * \\
(-1.69) \\
\varepsilon=-0.083\end{array}$ & $\begin{array}{c}-0.00019 * * \\
(-1.81) \\
\varepsilon=-0.087\end{array}$ & $\begin{array}{c}-0.00024 * * \\
(-2.16) \\
\varepsilon=-0.110\end{array}$ & $\begin{array}{c}-0.00023 * * * \\
(-2.34) \\
\varepsilon=-0.106\end{array}$ & $\begin{array}{c}-0.00023 * * * \\
(-2.34) \\
\varepsilon=-0.106\end{array}$ & $\begin{array}{c}-0.00018 * * \\
(-1.93) \\
\varepsilon=-0.083\end{array}$ & $\begin{array}{c}-0.00021 * * \\
(-2.17) \\
\varepsilon=-0.097\end{array}$ & $\begin{array}{c}-0.00024 * * * \\
(-2.48) \\
\varepsilon=-0.110\end{array}$ \\
\hline $\begin{array}{l}\text { MSA SES } \\
\text { Covariates }\end{array}$ & Yes*** & Yes** & Yes** & Yes*** & Yes** & Yes & Yes* & Yes* & Yes & Yes** \\
\hline $\begin{array}{l}\text { Lagged } \\
\text { Enforcement }\end{array}$ & No & Group 1*** & Group 2*** & Group3*** & Group 4*** & No & Group 1** & Group 2*** & Group3*** & Group 4*** \\
\hline Year Effects & Yes*** & Yes*** & Yes*** & Yes*** & Yes*** & Yes*** & Yes*** & Yes*** & Yes*** & Yes*** \\
\hline MSA Effects & Yes*** & Yes*** & Yes*** & Yes*** & Yes*** & Yes*** & Yes*** & Yes*** & Yes*** & Yes*** \\
\hline $\begin{array}{l}\text { MSA-Linear } \\
\text { Trend }\end{array}$ & No & No & No & No & No & Yes*** & Yes*** & Yes*** & Yes*** & Yes*** \\
\hline R-Squared & 0.939 & 0.945 & 0.948 & 0.950 & 0.945 & 0.960 & 0.962 & 0.966 & 0.964 & 0.964 \\
\hline Observations & 233 & 234 & 232 & 232 & 233 & 233 & 234 & 232 & 232 & 232 \\
\hline
\end{tabular}

Notes: All estimates are from weighted regressions. Dependent variable is $\log (\mathrm{A} / 1-\mathrm{A})$ where A is the total number of cocaine or heroin mentions in each MSA

divided by population. T-ratios are in parentheses. *** significant at 1 percent $* *$ significant at 5 percent $*$ significant at 10 percent. Group 1 enforcement variables are: lagged one year drug violation arrest rate and drug sale arrest rate. Group 2 enforcement variables are: lagged one year drug violation arrest rate and cocaine/heroin sale arrest rate. Group 3 enforcement variables are: lagged one year drug violation arrest rate and marijuana sale arrest rate. Group 4 enforcement variables are: one and two year lagged drug violation arrest rate and cocaine/heroin sale arrest rate. MSA SES covariates include: personal income, unemployment, male, black, other, Hispanic, age 16-24, age 25-54, high school graduate, college graduate, drug possession arrest rate, and log response rate. Elasticities are reported where the own-price coefficient is significant at 10 percent or less in a one-tailed test. 
Table 7

\section{Logistic Drug Episodes}

Cross Prices

\begin{tabular}{|c|c|c|c|c|c|c|}
\hline Specification & 1 & 2 & 3 & 4 & 5 & 6 \\
\hline Cocaine Price & $\begin{array}{c}-0.00357 * * * \\
(-3.34) \\
\varepsilon=-0.287\end{array}$ & $\begin{array}{c}-0.00279 * * * \\
(-2.49) \\
\varepsilon=-0.224\end{array}$ & $\begin{array}{c}-0.00243 * * * \\
(-3.45) \\
\varepsilon=-0.195\end{array}$ & $\begin{array}{c}-0.00191 * * * \\
(-2.75) \\
\varepsilon=-0.154\end{array}$ & $\begin{array}{c}-0.00202 * * * \\
(-3.02) \\
\varepsilon=-0.163\end{array}$ & $\begin{array}{c}-0.00240 * * * \\
(-3.64) \\
\varepsilon=-0.193\end{array}$ \\
\hline Heroin Price & $\begin{array}{c}-0.00022 * * * \\
(-2.57) \\
\varepsilon=-0.099\end{array}$ & $\begin{array}{c}-0.00021 * * \\
(-2.27) \\
\varepsilon=-0.094\end{array}$ & $\begin{array}{c}-0.00004 \\
(-0.78)\end{array}$ & $\begin{array}{c}-0.00005 \\
(-0.91)\end{array}$ & $\begin{array}{c}-0.00002 \\
(-0.47)\end{array}$ & $\begin{array}{c}-0.00003 \\
(-0.71)\end{array}$ \\
\hline $\begin{array}{l}1 \text { Year Lagged } \\
\text { Cocaine Price }\end{array}$ & - & $\begin{array}{c}-0.00144^{*} \\
(-1.30) \\
\varepsilon=-0.117\end{array}$ & - & $\begin{array}{c}-0.00208 * * * \\
(-3.14) \\
\varepsilon=-0.169\end{array}$ & - & $\begin{array}{c}-0.00216 * * * \\
(-3.64) \\
\varepsilon=-0.176\end{array}$ \\
\hline $\begin{array}{l}1 \text { Year Lagged } \\
\text { Heroin Price }\end{array}$ & - & $\begin{array}{c}-0.00015^{* *} \\
(-1.66) \\
\varepsilon=-0.074\end{array}$ & - & $\begin{array}{c}-0.00005 \\
(-0.99)\end{array}$ & - & $\begin{array}{c}-0.00001 \\
(-0.28)\end{array}$ \\
\hline $\begin{array}{l}\text { MSA Level } \\
\text { Covariates }\end{array}$ & Yes*** & Yes*** & Yes*** & Yes*** & Yes & Yes \\
\hline Year Effects & Yes & Yes & Yes*** & Yes*** & Yes*** & Yes*** \\
\hline MSA Effects & No & No & Yes*** & Yes*** & Yes*** & Yes*** \\
\hline MSA-Linear Trend & No & No & No & No & Yes*** & Yes*** \\
\hline R-Squared & 0.544 & 0.566 & 0.856 & 0.867 & 0.915 & 0.921 \\
\hline Observations & 244 & 242 & 245 & 242 & 245 & 242 \\
\hline
\end{tabular}

Notes: All estimates are from weighted regressions. Dependent variable is $\log (\mathrm{A} / 1-\mathrm{A})$ where $\mathrm{A}$ is the total number of drug related ED episodes in each MSA divided by population. T-ratios are in parentheses. ${ }^{* *}$ significant at 1 percent $* *$ significant at 5 percent $*$ significant at 10 percent. MSA SES covariates include: personal income, unemployment, male, black, other, Hispanic, age 16-24, age 25-54, high school graduate, college graduate, and log response rate. Elasticities are reported where the price coefficient is significant at 10 percent or less in a one-tailed test. 
Table 8

Logistic Cocaine Mentions

Cross Prices

\begin{tabular}{|c|c|c|c|c|c|c|}
\hline Specification & 1 & 2 & 3 & 4 & 5 & 6 \\
\hline Cocaine Price & $\begin{array}{c}-0.00387 * * * \\
(-2.34) \\
\varepsilon=-0.312\end{array}$ & $\begin{array}{c}-0.00293 * * \\
(-1.67) \\
\varepsilon=-0.236\end{array}$ & $\begin{array}{c}-0.00343 * * * \\
(-3.32) \\
\varepsilon=-0.276\end{array}$ & $\begin{array}{c}-0.00268 * * * \\
(-2.63) \\
\varepsilon=-0.216\end{array}$ & $\begin{array}{c}-0.00243 * * * \\
(-2.50) \\
\varepsilon=-0.196\end{array}$ & $\begin{array}{c}-0.00273 * * * \\
(-2.85) \\
\varepsilon=-0.220\end{array}$ \\
\hline Heroin Price & $\begin{array}{c}-0.00024^{*} \\
(-1.83) \\
\varepsilon=-0.108\end{array}$ & $\begin{array}{c}-0.00022 \\
(-1.56)\end{array}$ & $\begin{array}{c}0.00002 \\
(0.24)\end{array}$ & $\begin{array}{c}-0.00001 \\
(-0.08)\end{array}$ & $\begin{array}{c}0.00004 \\
(0.57)\end{array}$ & $\begin{array}{c}0.00001 \\
(0.22)\end{array}$ \\
\hline $\begin{array}{l}1 \text { Year Lagged } \\
\text { Cocaine Price }\end{array}$ & - & $\begin{array}{c}-0.00173 \\
(-1.00)\end{array}$ & - & $\begin{array}{c}-0.00267 * * * \\
(-2.74) \\
\varepsilon=-0.218\end{array}$ & - & $\begin{array}{c}-0.00244 * * * \\
(-2.82) \\
\varepsilon=-0.199\end{array}$ \\
\hline $\begin{array}{l}1 \text { Year Lagged } \\
\text { Heroin Price }\end{array}$ & - & $\begin{array}{c}-0.00016 \\
(-1.15)\end{array}$ & - & $\begin{array}{c}-0.00006 \\
(-0.73)\end{array}$ & - & $\begin{array}{c}-0.00001 \\
(-0.10)\end{array}$ \\
\hline $\begin{array}{l}\text { MSA Level } \\
\text { Covariates }\end{array}$ & Yes*** & Yes*** & Yes*** & Yes*** & Yes & Yes \\
\hline Year Effects & Yes & Yes & Yes*** & Yes*** & Yes*** & Yes*** \\
\hline MSA Effects & No & No & Yes*** & Yes*** & Yes*** & Yes*** \\
\hline MSA-Linear Trend & No & No & No & No & Yes*** & Yes*** \\
\hline R-Squared & 0.562 & 0.571 & 0.877 & 0.885 & 0.928 & 0.933 \\
\hline Observations & 245 & 242 & 245 & 242 & 245 & 242 \\
\hline
\end{tabular}

Notes: All estimates are from weighted regressions. Dependent variable is $\log (\mathrm{A} / 1-\mathrm{A})$ where A is the total number of cocaine mentions in each MSA divided by population. T-ratios are in parentheses. $* * *$ significant at 1 percent $* *$ significant at 5 percent $*$ significant at 10 percent. MSA SES covariates include: personal income, unemployment, male, black, other, Hispanic, age 16-24, age 25-54, high school graduate, college graduate, and log response rate. Elasticities are reported where the own-price coefficient is significant at 10 percent or less in a one-tailed test. 
Table 9

Logistic Heroin Mentions

Cross Prices

\begin{tabular}{|c|c|c|c|c|c|c|}
\hline Specification & 1 & 2 & 3 & 4 & 5 & 6 \\
\hline Heroin Price & $\begin{array}{c}-0.00057 * * \\
(-2.22) \\
\varepsilon=-0.257\end{array}$ & $\begin{array}{c}-0.00048 * * \\
(-1.77) \\
\varepsilon=-0.216\end{array}$ & $\begin{array}{c}-0.00028^{* *} \\
(-2.24) \\
\varepsilon=-0.126\end{array}$ & $\begin{array}{c}-0.00027 * * \\
(-2.14) \\
\varepsilon=-0.122\end{array}$ & $\begin{array}{c}-0.00016^{* *} \\
(-1.72) \\
\varepsilon=-0.072\end{array}$ & $\begin{array}{c}-0.00019 * * \\
(-1.89) \\
\varepsilon=-0.086\end{array}$ \\
\hline Cocaine Price & $\begin{array}{c}-0.00642 * * \\
(-2.57) \\
\varepsilon=-0.518\end{array}$ & $\begin{array}{c}-0.00607 * * \\
(-2.33) \\
\varepsilon=-0.490\end{array}$ & $\begin{array}{c}-0.00191 \\
(-1.54)\end{array}$ & $\begin{array}{c}-0.00174 \\
(-1.40)\end{array}$ & $\begin{array}{c}-0.00422 * * * \\
(-4.16) \\
\varepsilon=-0.340\end{array}$ & $\begin{array}{c}-0.00520 * * * \\
(-5.16) \\
\varepsilon=-0.419\end{array}$ \\
\hline $\begin{array}{l}1 \text { Year Lagged } \\
\text { Heroin Price }\end{array}$ & - & $\begin{array}{c}-0.00016 \\
(-0.65)\end{array}$ & - & $\begin{array}{c}-0.00017^{*} \\
(-1.43) \\
\varepsilon=-0.084\end{array}$ & 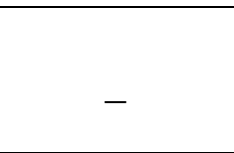 & $\begin{array}{c}-0.00003 \\
(-0.32)\end{array}$ \\
\hline $\begin{array}{l}1 \text { Year Lagged } \\
\text { Cocaine Price }\end{array}$ & - & $\begin{array}{c}-0.00100 \\
(-0.39)\end{array}$ & - & $\begin{array}{c}-0.00104 \\
(-0.89)\end{array}$ & - & $\begin{array}{c}-0.00362 * * * \\
(-3.88) \\
\varepsilon=-0.295\end{array}$ \\
\hline $\begin{array}{l}\text { MSA Level } \\
\text { Covariates }\end{array}$ & Yes*** & Yes*** & Yes*** & Yes*** & Yes* & Yes \\
\hline Year Effects & Yes*** & Yes** & Yes*** & Yes*** & Yes*** & Yes*** \\
\hline MSA Effects & No & No & Yes*** & Yes*** & Yes*** & Yes*** \\
\hline MSA-Linear Trend & No & No & No & No & Yes*** & Yes*** \\
\hline R-Squared & 0.561 & 0.558 & 0.923 & 0.924 & 0.963 & 0.966 \\
\hline Observations & 245 & 242 & 245 & 242 & 245 & 242 \\
\hline
\end{tabular}

Notes: All estimates are from weighted regressions. Dependent variable is $\log (\mathrm{A} / 1-\mathrm{A})$ where $\mathrm{A}$ is the total number of heroin mentions in each MSA divided by population. T-ratios are in parentheses. ${ }^{* * *}$ significant at 1 percent $* *$ significant at 5 percent $*$ significant at 10 percent. MSA SES covariates include: personal income, unemployment, male, black, other, Hispanic, age 16-24, age 25-54, high school graduate, college graduate, and log response rate. Elasticities are reported where the own-price coefficient is significant at 10 percent or less in a one-tailed test. 
Figure 1

\section{ED Drug Episodes and Cocaine Price}

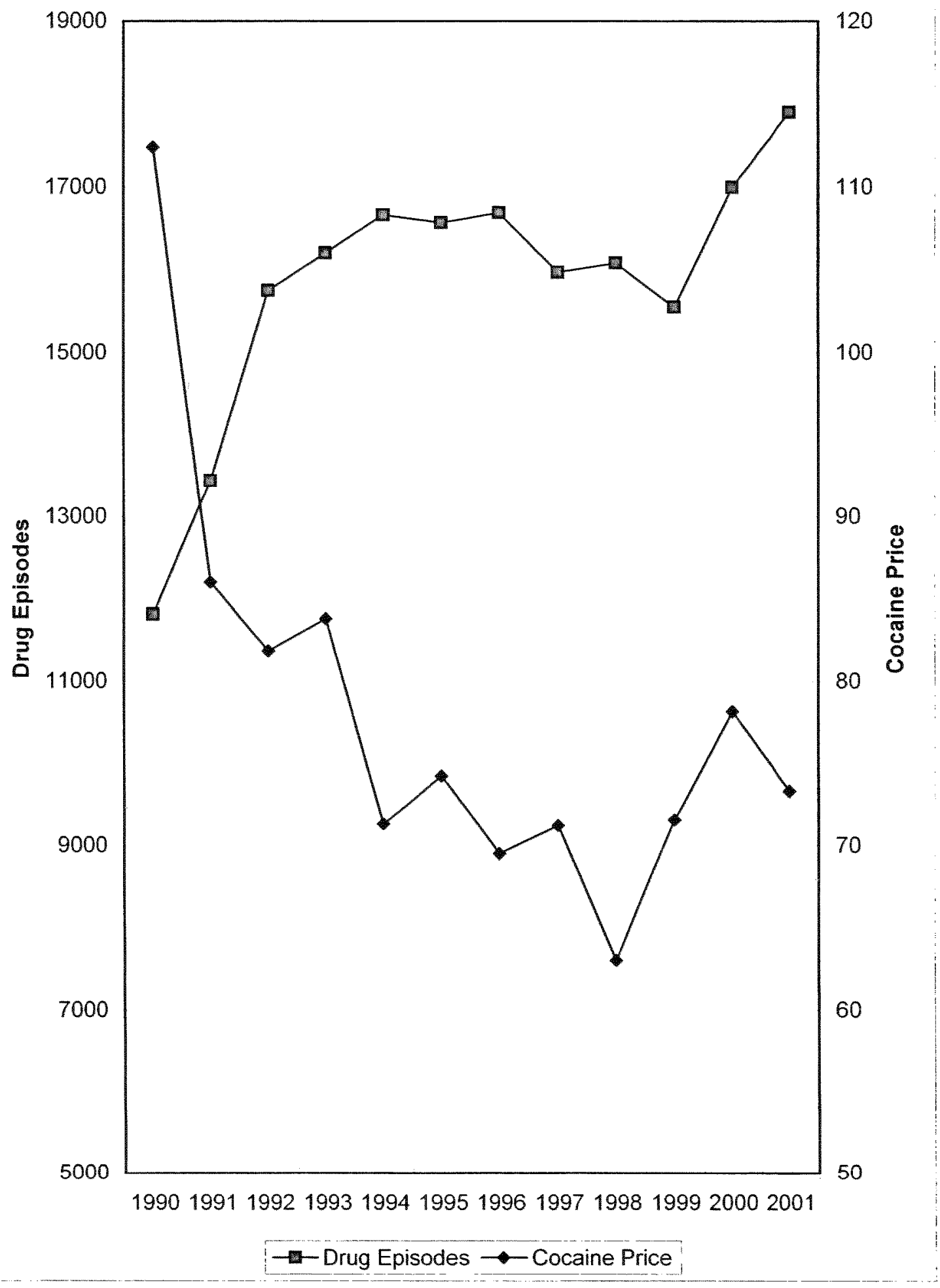


Figure 2

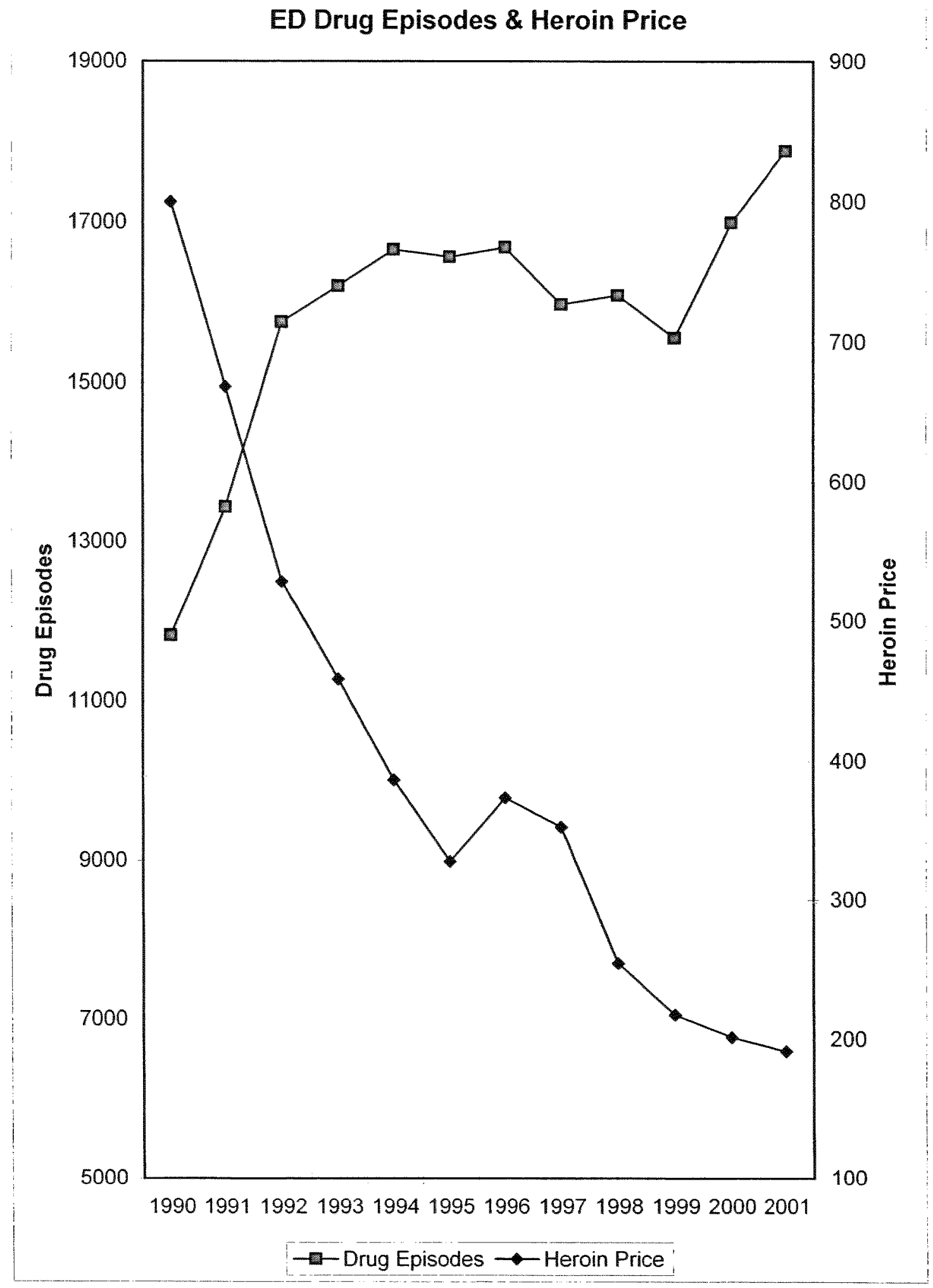


Figure 3

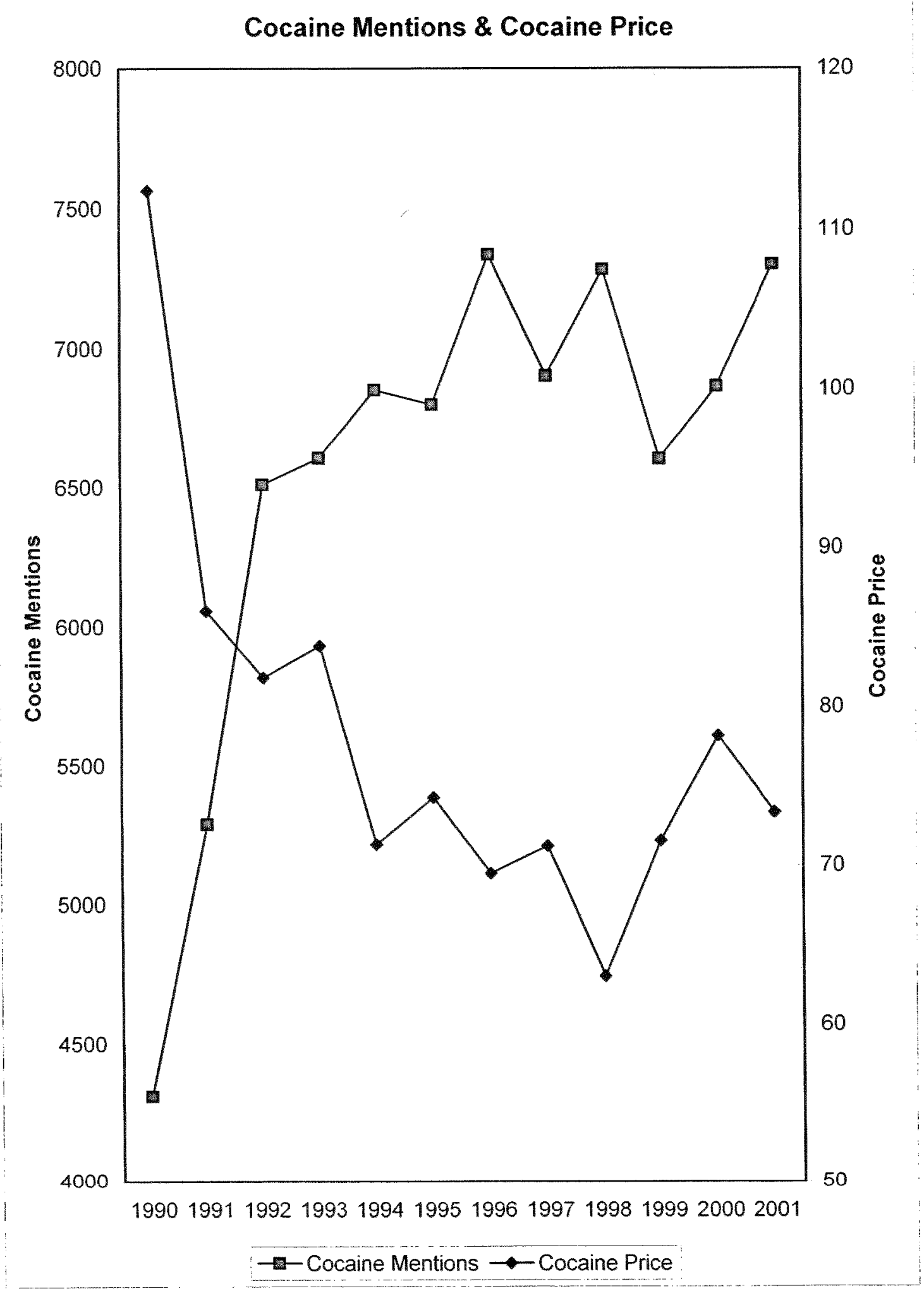


Figure 4

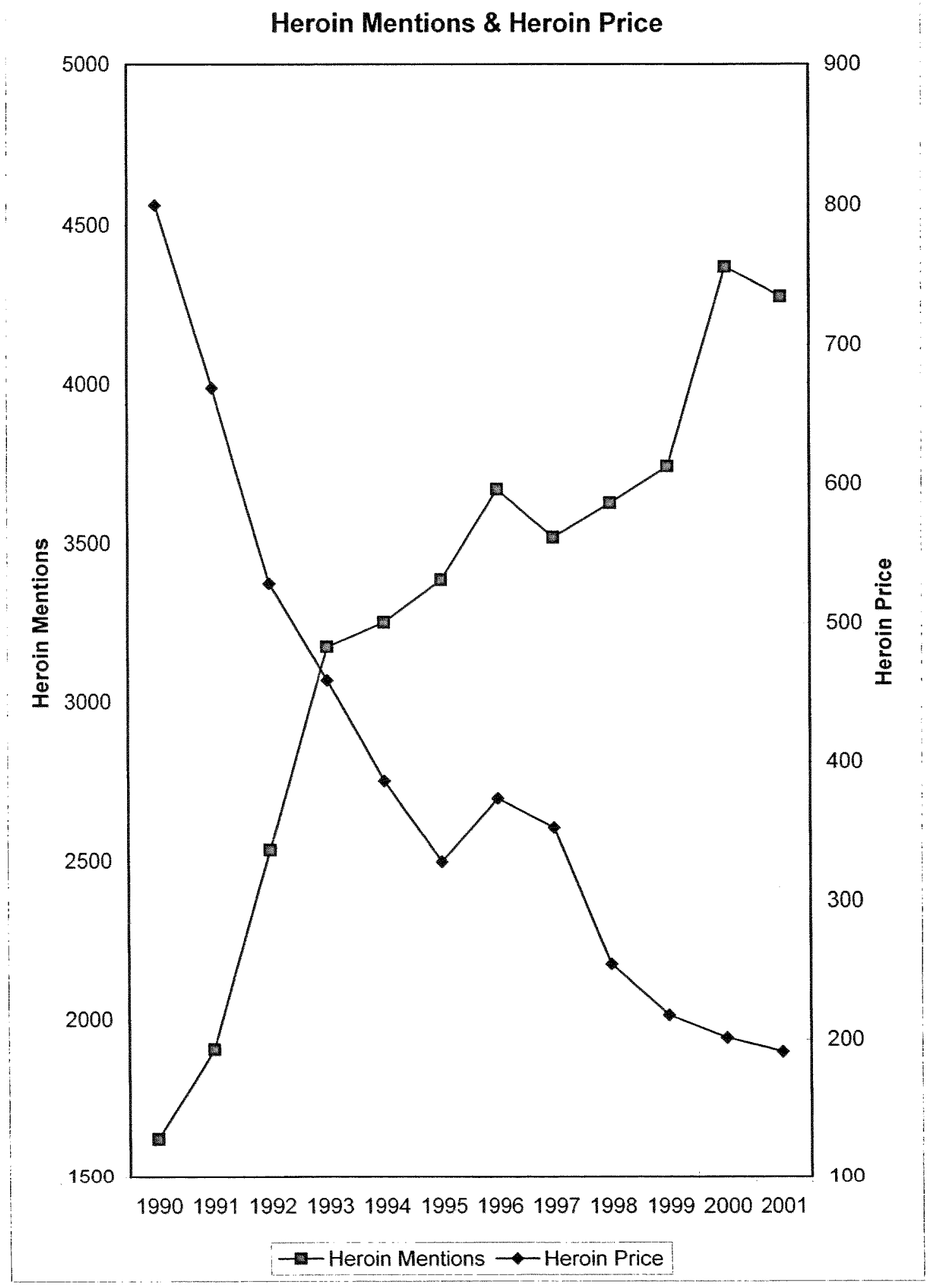

